\title{
Computer Automation of General-to-Specific Model Selection Procedures
}

\author{
By Hans-Martin Krolzig and David F. Hendry* \\ Institute of Economics and Statistics and Nuffield College, Oxford.
}

January 22, 2000

\begin{abstract}
That econometric methodology remains in dispute partly reflects the lack of clear evidence on alternative approaches. This paper reconsiders econometric model selection from a computerautomation perspective, focusing on general-to-specific reduction approaches, as embodied in the program PcGets (general-to-specific). Starting from a general linear, dynamic statistical model, which captures the essential data characteristics, standard testing procedures are applied to eliminate statistically-insignificant variables, using diagnostic tests to check the validity of the reductions, ensuring a congruent final model. As the joint issue of variable selection and diagnostic testing eludes most attempts at theoretical analysis, a simulation-based analysis of modelling strategies is presented. The results of the Monte Carlo experiments cohere with the established theory: PcGets recovers the DGP specification with remarkable accuracy. Empirical size and power of PcGets are close to what one would expect if the DGP were known.

JEL Classification: C51, C22.

Keywords: Econometric methodology; Model selection; Encompassing; Data mining; Monte Carlo experiments; Money demand; Consumption function.
\end{abstract}

\section{Introduction}

Despite the controversy surrounding econometric methodology, over the last three decades, the 'LSE' approach (see Hendry, 1993, for an overview) has emerged as a leading approach to econometric modelling. One of its main tenets is the concept of general-to-specific modelling: starting from a general dynamic statistical model, which captures the essential characteristics of the underlying data set, standard testing procedures are used to reduce its complexity by eliminating statistically-insignificant variables, checking the validity of the reductions at every stage in order to ensure the congruence of the selected model.

In this paper, we discuss a computer automation of such an econometric model-selection process which we call PcGets (general-to-specific). PcGets is an Ox Package (see Doornik, 1998, and Hendry and Krolzig, 1999a) designed for general-to-specific modelling, presently focusing on reduction approaches for linear, dynamic, regression models. The development of PcGets has been stimulated by Hoover and Perez (1999) who sought to evaluate the performance of Gets. To implement a 'general-tospecific' approach in a computer algorithm, all decisions have to be 'mechanized'. In doing so, Hoover and Perez highlighted some important advances in practical modelling, and our approach builds on these

\footnotetext{
${ }^{*}$ We grateful to Jurgen Doornik, Neil Ericsson, Jon Faust, Marianne Sensier and Rolf Tschernig and seminar participants at the CEF99, Norges Bank, and the Bank of Argentina for their comments. All the computations reported in this paper were carried out with the PcGets class in Ox. Financial support from the UK Economic and Social Research Council under grant L116251015 is gratefully acknowledged.
} 
by introducing further improvements. Given a general model, many reduction paths and strategies could be considered, some of which may lead to different terminal specifications, between which a choice must be made. Consequently, the reduction process is inherently iterative. When one round delivers multiple congruent contenders, encompassing can be used to test between these - usually non-nested - specifications, and only models which survive the encompassing step need be kept for further consideration. If multiple models still survive this 'testimation' process, their union forms a new general model, and the simplification process is re-applied. If that union repeats on the next round, a final selection is made using information criteria.

Our attempt to automate Gets throws further light on several methodological issues, and prompts some new ideas, which will be discussed in section 2. While the joint issue of variable selection and diagnostic testing using multiple criteria has eluded most attempts at theoretical analysis, computer automation of the model-selection process allows us to evaluate econometric model-selection strategies by simulation. Section 3 presents the results of some Monte Carlo experiments to investigate if the model-selection process works well or fails badly; their implications for the calibration of PcGets are also analyzed. The empirical illustrations presented in section 4 demonstrate the usefulness of PcGets for applied econometric research.

\section{The econometrics of model selection}

\subsection{Concepts}

The key issue for any model-selection procedure is the cost of search, since there are always bound to be mistakes in statistical inference: specifically, how bad does it get to search across many alternatives?

On the one hand, the conventional statistical analysis of repeated testing provides a pessimistic background: every test has a non-zero null rejection frequency (or size, if independent of nuisance parameters), and so type I errors accumulate. Setting a small size for every test can induce low power to detect the influences that really matter. The study by Lovell (1983) of trying to select a small relation (0 to 5 regressors) from a large database (up to 40 variables) suggested search had very high costs, leading to an adverse view of 'data mining'. Although Lovell did not consider a structured reduction approach among his methods, Gets has been criticized by Pagan (1987) on the grounds that the selection path may matter, and so the result is not 'path independent'. Indeed, Leamer (1983) claimed that 'the mapping is the message'. Moreover, 'pre-testing' is known to bias estimated coefficients, and may distort inference: see inter alia, Bock, Yancey and Judge (1973) and Judge and Bock (1978).

On the other hand, White (1990) showed that with sufficiently-rigorous testing, the selected model will converge to the data generating process (DGP). Thus, any 'overfitting' and mis-specification problems are primarily finite sample. Moreover, Mayo (1981) emphasized the importance of diagnostic test information being effectively independent of the sufficient statistics from which parameter estimates are derived. Also, Hendry (1995) argued that congruent models are the appropriate class within which to search, that encompassing resolves many instances of 'data mining', and that in econometrics, theory dependence has as many drawbacks as sample dependence, so modelling procedures are essential. Finally, Hoover and Perez (1999) reconsidered the Lovell (1983) experiments to evaluate the performance of Gets. Most important is their notion of commencing from the congruent general model by following a number of reduction search paths, terminated by either no further feasible reductions or significant diagnostic tests occurring. Hoover and Perez select among the surviving models the one which fits best. They show how much better a structured approach is than any method Lovell considered, suggesting that modelling per se need not be bad. Indeed, overall, the size of their selection procedure is close to 
that expected, and the power is reasonable. Thus, the case against model selection is far from proved.

Little research has focused on how to design model-search algorithms. To reduce search costs, any model-selection process must be designed to avoid getting stuck in a search path that initially inadvertently deletes variables that really do matter in the DGP, thereby retaining many other variables as proxies. Thus, it is imperative to explore multiple paths, although it is not known whether all possible paths should be searched. In order to meet this requirement, PcGets builds on the multi-path approach to Gets model selection in Hoover and Perez (1999). Equally, the search procedure must have a high probability of retaining the variables that do matter in the DGP. To achieve that, PcGets uses encompassing tests between alternative reductions. Balancing these objectives of small size and high power still involves a trade-off, but one that is dependent on the algorithm: the upper bound is probably determined by the famous lemma in Neyman and Pearson (1928). Nevertheless, to tilt the size-power balance favourably, sub-sample information is exploited building on the further major development in Hoover and Perez of investigating split samples for significance (as against constancy). Since non-central ' $t$ 'values diverge with increasing sample size, whereas central fluctuate around zero, the latter have a low probability of exceeding any given critical value in two sub-samples, even when those sample overlap. Thus, adventitiously-significant variables are revealed by their insignificance in one or both of the sub-samples.

PcGets embodies some further developments. First, PcGets undertakes 'pre-search' simplification F-tests to exclude variables from the general unrestricted model (GUM). Since variables found to be irrelevant on such tests are excluded from later analyses, these tests use a lenient significance level (such as $10 \%$ ), after which the GUM is reformulated. Next, a large number of possible paths from that GUM are investigated: reduction paths considered include both multiple deletions as well as single, so t and/or $F$ test statistics are used as simplification criteria. The third development concerns the encompassing step. All distinct contenders that are valid reductions are collected, and encompassing is then used to test between these (usually non-nested) specifications. Models which survive encompassing are retained; all encompassed equations are rejected. If multiple models survive this 'testimation' process, their union forms a new general model, and the selection process recommences. Such a process repeats till it reproduces the same union, then stops. Fourthly, the diagnostic tests require careful choice to ensure they characterize the salient attributes of congruency, are correctly sized, and do not overly restrict reductions. A further improvement concerns the model choice when mutually-encompassing distinct models survive the encompassing step. A minimum standard error rule, as used by Hoover and Perez (1999), will probably 'over-select' as it corresponds to retaining all variables that have $|t|>1$. Therefore, we employ information criteria which penalize the likelihood function for the number of parameters. Finally, subsample information is used to accord a 'reliability' score to variables, which investigators may use to guide their model choice. In Monte Carlo experiments, a 'progressive research strategy (PRS)' can be formulated in which decisions on the final model choice are based on the outcomes of the reliability measure.

\subsection{The multi-path reduction process of $P c G e t s$}

The starting point of the model-selection process is the general unrestricted model. The key issues concern its specification and congruence. The larger the initial regressor set, the more likely adventitious effects will be retained. But the smaller the GUM, the more likely key variables will be omitted. Further, the less orthogonality between variables, the more 'confusion' the algorithm faces, leading to a proliferation of mutual-encompassing models, so final choices may only differ marginally (e.g., lag 2 
versus 1). ${ }^{1}$ Finally, the initial specification must be congruent, so no mis-specification tests are failed at the outset. Empirically, the GUM would be revised if such tests rejected, and little is known about the consequences of doing so (although PcGets will enable such studies in the near future). In Monte Carlo experiments, the program automatically changes the significance levels of such tests, as discussed below.

The reduction path relies on a classical, sequential-testing approach. The number of paths is increased to try all single-variable deletions, as well as various block deletions from the GUM. Different critical values can be set for multiple and single selection tests, and for diagnostic tests. Denote by $\eta$ the significance level for the mis-specification tests (diagnostics) and by $\alpha$ the significance level for the selection t-tests (we ignore $\mathrm{F}$ tests for the moment). The corresponding $\mathrm{p}$-values of these are denoted $\widehat{\eta}$ and $\widehat{\alpha}$, respectively. During the specification search, the current specification is simplified only if no diagnostic test rejects its null. This corresponds to a likelihood-based model evaluation, where the likelihood function of model $\mathrm{M}$ is given by the density:

$$
L_{\mathrm{M}}\left(\boldsymbol{\theta}_{\mathrm{M}}\right)=\left\{\begin{array}{l}
f_{\mathrm{M}}\left(\mathbf{Y} ; \boldsymbol{\theta}_{\mathrm{M}}\right) \\
-\infty
\end{array} \quad \text { if } \min \left(\hat{\boldsymbol{\eta}}_{\mathrm{M}}\left(\mathbf{Y} ; \tilde{\boldsymbol{\theta}}_{\mathrm{M}}\right)-\boldsymbol{\eta}\right)\left\{\begin{array}{l}
\geq \\
<
\end{array}\right\} 0\right.
$$

where $f_{\mathrm{M}}\left(\mathbf{Y} ; \boldsymbol{\theta}_{\mathrm{M}}\right)$ is the probability density function (pdf) associated with model $\mathrm{M}$ at the parameter vector $\boldsymbol{\theta}_{M}$, for the sample $\mathbf{Y}$. The vector of test statistics p-values, $\hat{\boldsymbol{\eta}}_{\mathrm{M}}\left(\mathbf{Y} ; \tilde{\boldsymbol{\theta}}_{\mathrm{M}}\right)$, is evaluated at the maximum likelihood estimate $\widetilde{\boldsymbol{\theta}}_{M}$ under model $\mathrm{M}$, and mapped into its marginal rejection probabilities. So the pdf of model $\mathrm{M}$ is only accepted as the likelihood function if the sample information coheres with the underlying assumptions of the model itself.

In Monte Carlo experiments, PcGets sets the significance levels of the mis-specification tests endogenously: when a test of the DGP (or 'true model') reveals a significant diagnostic outcome (as must happen when tests have a non-zero size), the significance level is adjusted accordingly, where for the $k^{\text {th }}$ test:

$$
\eta_{k}=\left\{\begin{array}{c}
\bar{\eta}^{\prime \prime} \\
\bar{\eta}^{\prime} \\
0
\end{array}\right\} \text { if } \widehat{\eta}_{k, \mathrm{GUM}}\left(\mathbf{Y}, \tilde{\boldsymbol{\theta}}_{\mathrm{GUM}}\right) \in\left\{\begin{array}{cc}
{\left[\bar{\eta}^{\prime \prime}, 1\right]} & \text { 'desired significance level' } \\
{\left[\bar{\eta}^{\prime}, \bar{\eta}^{\prime \prime}\right)} & \text { 'reduced significance level' } \\
{\left[0, \bar{\eta}^{\prime}\right)} & \text { 'test excluded' }
\end{array}\right\}
$$

where $0<\bar{\eta}^{\prime}<\bar{\eta}^{\prime \prime}<1$ (in contrast, Hoover and Perez, 1999, drop such a test from the checking set, so an ever-increasing problem of that type may lurk undetected). It seems better to initially increase the nominal level for rejection, and if during any search path, that higher level is exceeded, then stop; we find that sometimes such GUM tests cease to be significant as reduction proceeds, and sometimes increase to reveal a flawed path.

The search path is ended by an encompassing step (see e.g., Mizon and Richard, 1986, and Hendry and Richard, 1989). Used as the last step of model selection, encompassing seems to help to control the size of the many path searches. When a given path eliminates a variable $x$ that matters, other variables proxy such an effect, leading to a 'spuriously large' and mis-specified model. However, some other paths are likely to retain $x$, and in the encompassing tests, the proxies will frequently be revealed as conditionally redundant, inducing a smaller final model, focused on the genuine causal factors.

\footnotetext{
${ }^{1}$ Some empirical examples for autoregressive-distributed lag (ADL) models and single-equation equilibrium-correction models $(\mathrm{EqCM})$ are presented in section 4.
} 
Stage I

Table 1 The PcGets algorithm.

\section{(1) Estimation and testing of the GUM}

(a) If all variables are significant, the GUM is the final model, and the algorithm stops;

(b) if a diagnostic test fails for the GUM, its significance level is adjusted or the test is excluded from the test battery during simplifications of the GUM;

(c) otherwise, search paths start by removing an insignificant variable, or a set of insignificant variables.

(2) Multiple reduction paths: sequential simplification and testing of the GUM

(a) If any diagnostic tests fail, that path is terminated, and the algorithm returns to the last accepted model of the search path:

(i) if the last accepted model cannot be further reduced, it becomes the terminal model of the particular search path;

(ii) otherwise, the last removed variable is re-introduced, and the search path continues with a new reduction by removing the next least-insignificant variable of the last accepted model.

(b) If all tests are passed, but one or more variables are insignificant, the least significant variable is removed: if that specification has already been tested on a previous path, the current search path is terminated;

(c) if all diagnostic tests are passed, and all variables are significant, the model is the terminal model of that search path.

\section{(3) Encompassing}

(a) If none of the reductions is accepted, the GUM is the final model;

(b) if only one model survives the testimation process, it is the final model;

(c) otherwise, the terminal models are tested against their union:

(i) if all terminal models are rejected, their union is the final model;

(ii) if exactly one of the terminal models is not rejected, it is the final model;

(iii) otherwise, rejected models are removed, and the remaining terminal models tested against their union:

1. if all remaining terminal models are rejected, their union is the final model;

2. if exactly one remaining terminal model is not rejected, it is the final model;

3. otherwise, the union of the 'surviving' models becomes the GUM of Stage II.

Stage II

(1) Estimation and testing of the GUM as in Stage I (significance levels remain fixed)

(2) Multiple reduction paths as in Stage I

(3) Encompassing and final model selection

(a) If only one model survives the testimation process of Stage II, it is the final model;

(b) otherwise, the terminal models of stage II are tested against their union:

(i) if all terminal models are rejected, their union is the final model.

(ii) if exactly one terminal model is not rejected, it is the final model.

(iii) otherwise, the set of non-dominated terminal models are reported or information criteria are applied to select a unique final model. 
The selection of the final model also improves upon Hoover and Perez (1999). Instead of selecting the best-fitting equation, PcGets focuses on encompassing testing between the candidate congruent selections. If a unique choice occurs, then the algorithm is terminated, otherwise, the union of the variables is formed as a new starting point for the reduction. Should that coincide with the previous union, then a model is selected by an information criterion (AIC, HQ, SC); otherwise the algorithm retries all the available paths again from that smaller union: if no simpler encompassing congruent model appears, final choice is by AIC, HQ or SC, etc. ${ }^{2}$ Table 1 records details of the basic algorithm.

To control the overall size of the model-selection procedure, two directions of extending the original algorithm were taken. First, the introduction before Stage I of block $(F)$ tests of groups of variables, ordered by their t-values in the GUM (but potentially according to economic theory). This set includes the overall F-test of all regressors to check that there is something to model. Variables that are insignificant at this step, usually at a low critical value, are eliminated from the analysis, and a smaller GUM is formulated. Secondly, Stage III was introduced as a check for potential over-selection in Stage II by a sub-sample split to eliminate problematic variables from the reduction search. This mimics the idea of recursive estimation, using the fact that a central $t$ statistic converges to zero (wandering around the origin), while a non-central t diverges. Thus, by chance the $i^{t h}$ variable could be significant for $T_{1}$ observations, yet the $j^{\text {th }}$ for $T>T_{1}$ if there is not too much sample overlap. Consequently, a progressive research strategy (shown as PRS below) can gradually eliminate 'adventitiously-significant' variables. The precise details of the resulting algorithm are shown in Table 2.

\subsection{Calibration of $P c G e t s$}

The 'testimation' process of PcGets depends on:

- choice of using pre-search F-test simplification;

- choice of the significance level $\kappa$ of these tests;

- choice of the simplification tests ( $\mathrm{t}$ and/or F);

- choice of the significance levels $\boldsymbol{\alpha}$ of the simplification tests;

- choice of the $n$ diagnostics for the test battery;

- choice of the parameters of the diagnostic tests;

- choice of the significance levels $\boldsymbol{\eta}$ of the $n$ diagnostics;

- choice of the significance levels $\gamma$ of the encompassing tests;

- choice of the sub-sample split;

- choice of the significance level $\boldsymbol{\delta}$ of the sub-sample tests.

The choice of the diagnostic tests concerns which alternatives to test against, as well as the number of tests to conduct. Since significant diagnostic tests terminate search paths, they act as constraints on moving away from the GUM. If a search is to progress towards simplification, therefore, it is crucial that such tests have the correct size. The overall significance level of the test battery matters, and this is determined by the choice of the individual significance levels of each diagnostic, and the number of such tests. The choice of critical values for selection tests is also important for the success of PcGets:

\footnotetext{
${ }^{2}$ The information criteria are defined as follows:
}

$$
\begin{array}{r}
A I C=-2 \log L / T+2 n / T, \\
S C=-2 \log L / T+n \log (T) / T, \\
H Q=-2 \log L / T+2 n \log (\log (T)) / T,
\end{array}
$$

where $L$ is the maximized likelihood, $n$ is the number of parameters and $T$ is the sample size: see e.g., Sawa (1978) and Chow (1981). 
Table 2 Additions to the basic PcGets algorithm.

Stage 0

\section{(1) Pre-simplification and testing of the GUM}

(a) If a diagnostic test fails for the GUM, the significance level of that test is adjusted, or the test is excluded from the test battery during simplifications of the GUM;

(b) if all variables are significant, the GUM is the final model, and the algorithm stops;

(c) otherwise, F-tests of sets of individually-insignificant variables are conducted:

(i) if one or more diagnostic tests fails, that F-test reduction is cancelled, and the algorithm returns to the previous step;

(ii) if all diagnostic tests are passed, the blocks of variables that are insignificant are removed and a simpler GUM specified;

(iii) if all diagnostic tests are passed, and all blocks of variables are insignificant, the null model is the final model.

Stage III

\section{(1) Post-selection sub-sample evaluation}

(a) Test the significance of every variable in the final model from Stage II in two overlapping sub-samples (e.g., the first and last $r \%$ ):

(i) if a variable is significant overall and both sub-samples, accord it 100\% reliable;

(ii) if a variable is significant overall and in one sub-sample, accord it 75\% reliable;

(iii) if a variable is significant overall and in neither sub-sample, accord it 50\% reliable;

(iv) if a variable is insignificant overall but in both sub-samples, accord it $50 \%$ reliable;

(v) if a variable is insignificant overall and in only one sub-sample, accord it $25 \%$ reliable;

(vi) if a variable is insignificant overall and in neither sub-sample, accord it $0 \%$ reliable.

the tighter the size, the fewer the 'spurious inclusions of irrelevant', and the more the 'false exclusions of relevant variables'. In the final analysis, the calibration of PcGets depends on the characteristics of the user: if PcGets is employed as a first 'pre-selection' step of a user's research agenda, the optimal values of $\kappa, \boldsymbol{\alpha}, \gamma$ and $\delta$ may be higher than when the focus is on controlling the overall size of the selection process.

In section 3, we will use simulation techniques to investigate the calibration of PcGets for the operational characteristics of the diagnostic tests, the selection probabilities of DGP variables, and the deletion probabilities of non-DGP variables. However, little research has been undertaken to date to 'optimize' any of the choices, or to investigate the impact on model selection of their interactions.

\subsection{Limits to PcGets}

Davidson and Hendry (1981, p.257) mentioned four main problems in the general-to-specific methodology: (i) the chosen 'general' model can be inadequate, comprising a very special case of the DGP; (ii) data limitations may preclude specifying the desired relation; (iii) the non-existence of an optimal sequence for simplifying leaves open the choice of reduction path; and (iv) potentially-large type-II error probabilities of the individual tests may be needed to avoid a high type-I error of the overall sequence. By adopting the 'multiple path' development of Hoover and Perez (1999), and implementing a range of potentially important improvements, PcGets overcomes some of problems associated with points (iii) 
and (iv). However, the empirical success of PcGets will depend crucially on the creativity of the researcher in specifying the general model and the feasibility of estimating it from the available data, and these aspects are beyond the capabilities of the program, other than the diagnostic tests serving their usual role of revealing model mis-specification.

There is a central role for economic theory in the modelling process in 'prior specification', 'prior simplification', and suggesting admissible data transforms. The first of these relates to the inclusion of potentially-relevant variables, the second to the exclusion of irrelevant effects, and the third to the appropriate formulations in which the influences to be included are entered, such as log or ratio transforms etc., differences and cointegration vectors, and any likely linear transformations that might enhance orthogonality between regressors. The 'LSE approach' argued for a close link of theory and model, and explicitly opposed 'running regressions on every variable on the database' as in Lovell (1983) (see e.g., Hendry and Ericsson, 1991a). PcGets focuses on general-to-simple reductions for linear, dynamic, regression models, and economic theory usually provides little evidence for specifying the lag length in empirical macro-models. Even when the theoretical model is dynamic, the lags are usually chosen either for analytical convenience (e.g., first-order differential equation systems), or to allow for certain desirable features (as in the choice of a linear second-order single-equation model to replicate cycles). Therefore, we adopt the approach of starting with an unrestricted rational lag model with a maximal lag length set according to available evidence (e.g., as 4 or 5 for quarterly time series, to allow for seasonal dynamics). Prior analysis remains essential for appropriate parameterizations; functional forms; choice of variables, lag lengths; and indicator variables (including seasonals, special events, etc.). The present performance of PcGets on previously-studied empirical problems is impressive, even when the GUM is specified in highly inter-correlated, and probably non-stationary, levels. Orthogonalization helps notably in selecting a unique representation; as does validly reducing the initial GUM. Hopefully, PcGets' support in automating the reduction process will enable researchers to concentrate their efforts on designing the GUM: that could again significantly improve the empirical success of the algorithm.

\subsection{Integrated variables}

To date, PcGets conducts all inferences as $\mathrm{I}(0)$. Most selection tests will in fact be valid even when the data are I(1), given the results in, say, Sims, Stock and Watson (1990). Only t- or F-tests for an effect that corresponds to a unit root require non-standard critical values. The empirical examples on I(1) data provided below do not reveal problems, but in principle it would be useful to implement cointegration tests and appropriate transformations after stage 0 , and prior to stage I reductions.

Similarly, Wooldridge (1999) shows that diagnostic tests on the GUM (and presumably simplifications thereof) remain valid even for integrated time series.

\section{Some Monte Carlo results}

\subsection{Aim of the Monte Carlo}

Although the sequential nature of PcGets and its combination of variable-selection and diagnostic testing eludes most attempts at theoretical analysis, the properties of the PcGets model-selection process can be evaluated in Monte Carlo (MC) experiments. In the MC considered here, we particularly aim to measure the 'size' and 'power' of the PcGets model-selection process. By power and size, we mean the inclusion in the final model of variables that do (do not) enter the DGP.

First, the properties of the diagnostic tests under the potential influence of nuisance regressors are 
investigated. Based on these results, a decision can be made as to which diagnostics to include in the test battery. Then the 'size' and 'power' of PcGets is compared to the empirical and theoretical properties of a classical t-test. Finally we analyze how the 'success' and 'failure' of PcGets are affected by the choice of: (i) the significance levels $\boldsymbol{\eta}$ of the diagnostic tests; and (ii) the significance levels $\boldsymbol{\alpha}$ of the specification tests.

\subsection{Design of the Monte Carlo}

The Monte Carlo simulation study of Hoover and Perez (1999) considered the Lovell database, which embodies many dozens of relations between variables as in real economies, and is of the scale and complexity that can occur in macro-econometrics: the rerun of those experiments using PcGets is discussed in Hendry and Krolzig (1999b). In this paper, we follow a simpler approach, which however, allows an analytical assessment of the simulation findings. The MC reported here uses only stages I and II in table 1: Hendry and Krolzig (1999b) show the additional improvements that can result from adding stages 0 and III to the study in Hoover and Perez (1999).

The DGP is a Gaussian $A D L(1,1)$ model, where the strongly-exogenous variables are Gaussian white-noise processes:

$$
\begin{array}{ll}
y_{t}=\beta_{0,1} y_{t-1}+\sum_{k=1}^{10} \sum_{i=0}^{1} \beta_{k, i} x_{k, t-i}+\mu+u_{t}, & u_{t} \sim \operatorname{IN}[0,1], \\
x_{t}=v_{t}, & v_{t} \sim \mathbb{I N}_{10}\left[\mathbf{0}, \mathbf{I}_{10}\right] \quad \text { for } t=1, \ldots, T,
\end{array}
$$

where $\beta_{1,0}=2 / \sqrt{T}, \beta_{2,0}=3 / \sqrt{T}, \beta_{3,0}=4 / \sqrt{T}, \beta_{4,0}=6 / \sqrt{T}, \beta_{5,0}=8 / \sqrt{T}$, and all other parameters are zero.

The correct specification is:

$$
y_{t}=\sum_{k=1}^{5} \beta_{k, 0} x_{k, t}+u_{t} .
$$

The sample size $T$ is 100 or 1000 and the number of replications $M$ is 1000 .

The orthogonality of the regressors allows an easier analysis. Recall that the t-test of the null $\beta_{k}=0$ versus the alternative $\beta_{k} \neq 0$ is given by:

$$
\mathrm{t}_{k}=\frac{\widehat{\beta}_{k}}{\widehat{\sigma}_{\beta_{k}}}=\frac{\widehat{\beta}_{k}}{\sqrt{\widehat{\sigma}_{\varepsilon}^{2}\left(\mathbf{X}^{\prime} \mathbf{X}\right)_{k k}^{-1}}}=\frac{\widehat{\beta}_{k} / \sqrt{\sigma_{\varepsilon}^{2}\left(\mathbf{X}^{\prime} \mathbf{X}\right)_{k k}^{-1}}}{\sqrt{\widehat{\sigma}_{\varepsilon}^{2} / \sigma_{\varepsilon}^{2}}} .
$$

The population value of the $t-$ statistic is given by:

$$
\mathrm{t}_{k}^{*}=\frac{\beta_{k}}{\sigma_{\beta_{k}}}=\frac{\beta_{k}}{T^{-\frac{1}{2}} Q_{k k}^{-1 / 2} \sigma_{\varepsilon}},
$$

where the moment matrix $Q=\lim _{T \rightarrow \infty}\left(T^{-1} \mathbf{X}^{\prime} \mathbf{X}\right)$ is assumed to exist. Since the regressors are orthogonal, we have that $\widehat{\beta}_{k}=\widehat{\sigma}_{x_{k} y} / \widehat{\sigma}_{k}^{2}$ and $\widehat{\sigma}_{\beta_{k}}^{2}=\widehat{\sigma}_{\varepsilon}^{2} /\left(T \widehat{\sigma}_{k}^{2}\right)$ :

$$
\mathrm{t}_{k}=\frac{\widehat{\beta}_{k}}{\widehat{\sigma}_{\beta_{k}}}=\sqrt{T} \widehat{\beta}_{k} \frac{\widehat{\sigma}_{k}}{\widehat{\sigma}_{\varepsilon}} .
$$

Thus the non-zero population t-values are $2,3,4,6,8$. In the general model, 17 of 22 regressors are nuisance. 
Table 3 Test battery.

\begin{tabular}{|l|l|l|l|}
\hline Test & Alternative & Statistic & Sources \\
\hline \hline $\begin{array}{l}\text { Chow }\left(\tau_{1} T\right) \\
\text { Chow }\left(\tau_{2} T\right)\end{array}$ & Predictive failure over a subset of $\left(1-\tau_{1}\right) T$ obs. & $F\left(\left(1-\tau_{1}\right) T, \tau_{1} T-k\right)$ & Chow (1960, p.594-595), \\
portmanteau $(r)$ & $r$-th order residual autocorrelation & $\chi^{2}(r)$ & Hendry (1979) \\
\hline normality test & Skewness and excess kurtosis & $\chi^{2}(2)$ & Box and Pierce (1970) \\
& & $F(p, T-k-p)$ & Godque and Bera (1980), \\
& Doornik and Hansen (1994)
\end{tabular}

\subsection{Evaluation of the Monte Carlo}

The evaluation of Monte Carlo experiments always involves measurement problems: see Hendry (1984). A serious problem here is that, with some positive probability, the GUM - and the 'truth' - will get rejected $a b$ initio on diagnostic tests. Tests are constructed to have non-zero nominal size under their null, so sometimes the truth will be rejected: and the more often, the more tests that are used. Three possible strategies suggest themselves: one rejects that data sample, and randomly re-draws; one changes the rejection level of the 'offending' test; or one re-specifies a more general GUM which is congruent. We consider these alternatives in turn.

Hoover and Perez (1999) use a '2-significant test rejections' criterion to discard a sample and redraw, which probably slightly favours the performance of Gets. In our MC with PcGets, the problem is 'solved' by endogenously adjusting the significance levels of tests that reject the GUM (e.g., $1 \%$ to $0.1 \%$ ). Such a 'solution' is feasible in an MC, but metaphysical in reality, as one could never know that a sample from an economy was 'unrepresentative', since time series are not repeatable. Thus, an investigator could never 'know' that the DGP was simpler empirically than the data suggest - although such a finding might gradually emerge in a PRS - and would probably generalize the initial GUM. We do not adopt that solution here, partly because of the difficulties inherent in the constructive use of diagnostic test rejections, and partly because it is moot whether the PcGet algorithm 'fails by overfitting' on such aberrant samples, when in a non-replicable world, one would conclude that such features really were aspects of the DGP. Notice that fitting the 'true' equation, then testing it against such alternatives, would also lead to rejection in this setting, unless the investigator knew the truth, and knew that she knew it, so no tests were needed. While more research is undoubtedly needed on cases where the DGP would be rejected against the GUM, here we allow PcGets to adjust significance levels endogenously.

Another major decision concerns the basis of comparison: the 'truth' seems to be a natural choice, and both Lovell (1983) and Hoover and Perez (1999) measure how often the search finds the DGP exactly - or nearly. Nevertheless, we believe that 'finding the DGP exactly' is not a good choice of comparator, because it implicitly entails a basis where the truth is known, and one is certain it is the truth. Rather, to isolate the costs of selection per se, we seek to match probabilities with testing the truth. In each replication, the correct DGP equation is fitted, and the same selection criteria applied. We then compare the retention rates for DGP variables from Gets with those that occur when no search is needed, namely when inference is conducted once for each DGP variable, and additional (non-DGP) variables are retained zero percent of the time. 
Table 4 Power and Size I.

\begin{tabular}{|c|rrrrr|rrr|cr|ccr|}
\hline & \multicolumn{7}{|c|}{ PcGets } & \multicolumn{3}{|c|}{$t$-test: simulated } & \multicolumn{3}{|c|}{$t$-test: theoretical } \\
\hline \hline$\alpha$ & 0.05 & 0.05 & 0.05 & 0.05 & 0.01 & 0.05 & 0.05 & 0.01 & 0.05 & 0.05 & 0.01 \\
$\eta$ & 0.05 & 0.01 & 0.00 & 0.01 & 0.01 & & & & & & \\
& AIC & AIC & AIC & AIC & AIC & & & & & & \\
$T, \nu$ & 100 & 100 & 100 & 1000 & 100 & 100 & 1000 & 100 & 100 & 1000 & 100 \\
\hline$t=0$ & 0.0812 & 0.0686 & 0.0646 & 0.0521 & 0.0189 & & & & 0.0500 & 0.0500 & 0.0100 \\
& 0.0022 & 0.0021 & 0.0019 & 0.0017 & 0.0010 & & & & & & \\
$t=2$ & 0.5090 & 0.4930 & 0.4910 & 0.5100 & 0.2820 & 0.4730 & 0.5010 & 0.2580 & 0.5083 & 0.5152 & 0.2713 \\
& 0.0158 & 0.0158 & 0.0158 & 0.0158 & 0.0142 & & & & & & \\
$t=3$ & 0.8070 & 0.8020 & 0.8010 & 0.8340 & 0.6210 & 0.8120 & 0.8360 & 0.6130 & 0.8440 & 0.8502 & 0.6459 \\
& 0.0125 & 0.0125 & 0.0126 & 0.0118 & 0.0153 & & & & & & \\
$t=4$ & 0.9750 & 0.9720 & 0.9710 & 0.9880 & 0.9000 & 0.9760 & 0.9850 & 0.9020 & 0.9773 & 0.9791 & 0.9127 \\
& 0.0049 & 0.0049 & 0.0053 & 0.0034 & 0.0095 & & & & & & \\
$t=6$ & 0.9990 & 0.9990 & 0.9990 & 1.0000 & 0.9990 & 1.0000 & 1.0000 & 0.9990 & 1.0000 & 1.0000 & 0.9996 \\
& 0.0010 & 0.0010 & 0.0010 & 0.0000 & 0.0010 & & & & & & \\
$t=8$ & 1.0000 & 1.0000 & 1.0000 & 1.0000 & 1.0000 & 1.0000 & 1.0000 & 1.0000 & 1.0000 & 1.0000 & 1.0000 \\
& 0.0000 & 0.0000 & 0.0000 & 0.0000 & 0.0000 & & & & & & \\
\hline
\end{tabular}

\subsection{Diagnostic tests}

PcGets records the rejection frequencies of both specification and mis-specification tests for the DGP, the initial GUM, and the various simplifications thereof based on the selection rules. Figure 1 displays QQ plots of the empirical distributions of seven potential mis-specification tests for the estimated correct specification, the general model, and the finally-selected model. Some strong deviations from the theoretical distributions (diagonal) are evident: the portmanteau statistic (see Box and Pierce, 1970) rejects serial independence of the errors too often in the correct specification, never in the general, and too rarely in the final model. The hetero-x test (see White, 1980) was faced with degrees of freedom problems for the GUM, but anyway does not look good for the true and final model either. This incorrect finite-sample size of the diagnostic tests induces an excessively-early termination of any search path, so results in an increased overall size for variable selection. For these reasons, we decided to exclude the portmanteau and the hetero-x diagnostics from the test battery of statistics. Thus, the following results are based on the five remaining diagnostic tests in table 3.

Figure 2 demonstrates that for large samples $(T=1000)$, the empirical distributions of the test statistics are unaffected by the strongly-exogenous nuisance regressors. For small samples $(T=100)$, the properties of the mis-specification tests are still satisfactory and (except for the heteroscedasticity test) close to the distributions of the test statistics under the null of the true model. Although Monte Carlo is always problem dependent, our findings cohere with what theory we have: the nuisance regressors do not increase the overall procedure size greatly, despite many paths being searched.

\subsection{Size and power of variable selection}

Simplification can at best eliminate the nuisance regressors all or most of the time (size), yet retain the substance nearly as often as the DGP: it cannot beat that. The metric to judge the costs of reduction and of mis-specification testing was noted above. The probability is low of detecting an effect that has a scaled population t-value of 2 or less in absolute value when the empirical selection criterion is larger. This suggests weighting the 'failure' of PcGets in relation to a variable's importance, statistically and economically. Then, 'missing' a variable with $|t|<2$ would count for less than missing an effect with $|t|>4$ (say). With such a baseline, low signal-noise variables will still rarely be selected, but that is attributable as a cost of inference, not a flaw of Gets type searches. 
Table 5 Power and Size II: The effects of information criteria .

\begin{tabular}{|c|rrr|rrr|rr|r|r|r|}
\hline & \multicolumn{7}{|c|}{ PcGets } & \multicolumn{1}{|c|}{$t$-test: simulated } & $t$-test: theoretical \\
\hline \hline$\alpha$ & 0.05 & 0.05 & 0.05 & 0.01 & 0.01 & 0.01 & 0.05 & 0.01 & 0.05 & 0.01 \\
& AIC & HQ & SC & AIC & HQ & SC & & & & \\
\hline$t=0$ & 0.0686 & 0.0679 & 0.0677 & 0.0189 & 0.0183 & 0.0185 & & & 0.0500 & 0.0100 \\
& 0.0021 & 0.0019 & 0.0019 & 0.0010 & 0.0010 & 0.0010 & & & & \\
$t=2$ & 0.4930 & 0.4930 & 0.4930 & 0.2820 & 0.2810 & 0.2820 & 0.4730 & 0.2580 & 0.5083 & 0.2713 \\
& 0.0158 & 0.0158 & 0.0158 & 0.0142 & 0.0142 & 0.0142 & & & & \\
$t=3$ & 0.8020 & 0.8020 & 0.8020 & 0.6210 & 0.6220 & 0.6200 & 0.8120 & 0.6130 & 0.8440 & 0.6459 \\
& 0.0125 & 0.0126 & 0.0126 & 0.0153 & 0.0153 & 0.0154 & & & & \\
$t=4$ & 0.9720 & 0.9720 & 0.9720 & 0.9000 & 0.9000 & 0.8980 & 0.9760 & 0.9020 & 0.9773 & 0.9127 \\
& 0.0049 & 0.0052 & 0.0053 & 0.0095 & 0.0096 & 0.0096 & & & & \\
$t=6$ & 0.9990 & 0.9990 & 0.9990 & 0.9990 & 0.9990 & 0.9990 & 1.0000 & 0.9990 & 1.0000 & 0.9996 \\
& 0.0010 & 0.0010 & 0.0010 & 0.0010 & 0.0010 & 0.0010 & & & & \\
$t=8$ & 1.0000 & 1.0000 & 1.0000 & 1.0000 & 1.0000 & 1.0000 & 1.0000 & 1.0000 & 1.0000 & 1.0000 \\
& 0.0000 & 0.0000 & 0.0000 & 0.0000 & 0.0000 & 0.0000 & & & & \\
\hline
\end{tabular}

All MC experiments use $\eta=0.01$ and $T=\nu=100$

Table 6 Power and Size III: The effects of a progressive research strategy .

\begin{tabular}{|c|rrr|rr|rr|}
\hline & \multicolumn{3}{|c|}{ PcGets } & \multicolumn{2}{|c|}{$t$-test: simulated } & \multicolumn{2}{|c|}{$t$-test: theoretical } \\
\hline \hline$\alpha$ & 0.05 & 0.05 & 0.01 & 0.05 & 0.01 & 0.05 & 0.01 \\
& $\mathrm{SC}$ & $\mathrm{HK}$ & $\mathrm{SC}$ & & & & \\
\hline$t=0$ & 0.0477 & 0.0479 & 0.0088 & & & 0.0500 & 0.0100 \\
& 0.0015 & 0.0015 & 0.0006 & & & & \\
$t=2$ & 0.4080 & 0.4087 & 0.1538 & 0.4730 & 0.2580 & 0.5083 & 0.2713 \\
& 0.0140 & 0.0140 & 0.0106 & & & & \\
$t=3$ & 0.7330 & 0.7327 & 0.4278 & 0.8120 & 0.6130 & 0.8440 & 0.6459 \\
& 0.0124 & 0.0125 & 0.0147 & & & & \\
$t=4$ & 0.9390 & 0.9390 & 0.7645 & 0.9760 & 0.9020 & 0.9773 & 0.9127 \\
& 0.0061 & 0.0061 & 0.0125 & & & & \\
$t=6$ & 0.9980 & 0.9980 & 0.9865 & 1.0000 & 0.9990 & 1.0000 & 0.9996 \\
& 0.0012 & 0.0012 & 0.0034 & & & & \\
$t=8$ & 1.0000 & 1.0000 & 1.0000 & 1.0000 & 1.0000 & 1.0000 & 1.0000 \\
& 0.0000 & 0.0000 & 0.0000 & & & & \\
\hline
\end{tabular}

All MC experiments use $\eta=0.01$ and $T=\nu=100$

In the following, we measure the outcome of PcGets by comparing its power and size with that of classical t-tests applied once to the 'true model', or DGP equation. The power function of a t-test of size $\alpha$ for including the $k^{\text {th }}$ variable $x_{k, t}$ with coefficient $\beta_{k, 0} \neq 0$ is given by:

$$
\operatorname{Pr}\left(\text { 'Include } x_{k, t} \text { ' } \mid \beta_{k, 0} \neq 0\right)=\operatorname{Pr}\left(\left|\mathrm{t}_{k}\right| \geq c_{\alpha} \mid \beta_{k, 0} \neq 0\right),
$$

when:

$$
\operatorname{Pr}\left(\left|t_{k}\right| \geq c_{\alpha} \mid \beta_{k, 0}=0\right)=\alpha .
$$

The rejection probability is given by a non-central $\mathrm{t}$ distribution with $\nu$ degrees of freedom and noncentrality parameter $\psi$, which can be approximated by a normal distribution $\Phi(x)$ (see Abramowitz and Stegun, 1970), where:

$$
x=\frac{\mathrm{t}\left(1-\frac{1}{4 \nu}\right)-\psi}{\left(1+\frac{\mathrm{t}^{2}}{2 \nu}\right)^{\frac{1}{2}}} .
$$

The power of a t-test with size $\alpha$ and $\nu$ degrees of freedom is then given by the parametric variation of the population t-value in:

$$
\operatorname{Pr}\left(\text { 'Include } x_{k, t} \mid \beta_{k, 0} \neq 0\right)=\operatorname{Pr}\left(-\mathrm{t}_{k} \leq c_{\alpha} \mid \beta_{k, 0} \neq 0\right)+\operatorname{Pr}\left(\mathrm{t}_{k} \geq c_{\alpha} \mid \beta_{k, 0} \neq 0\right) .
$$




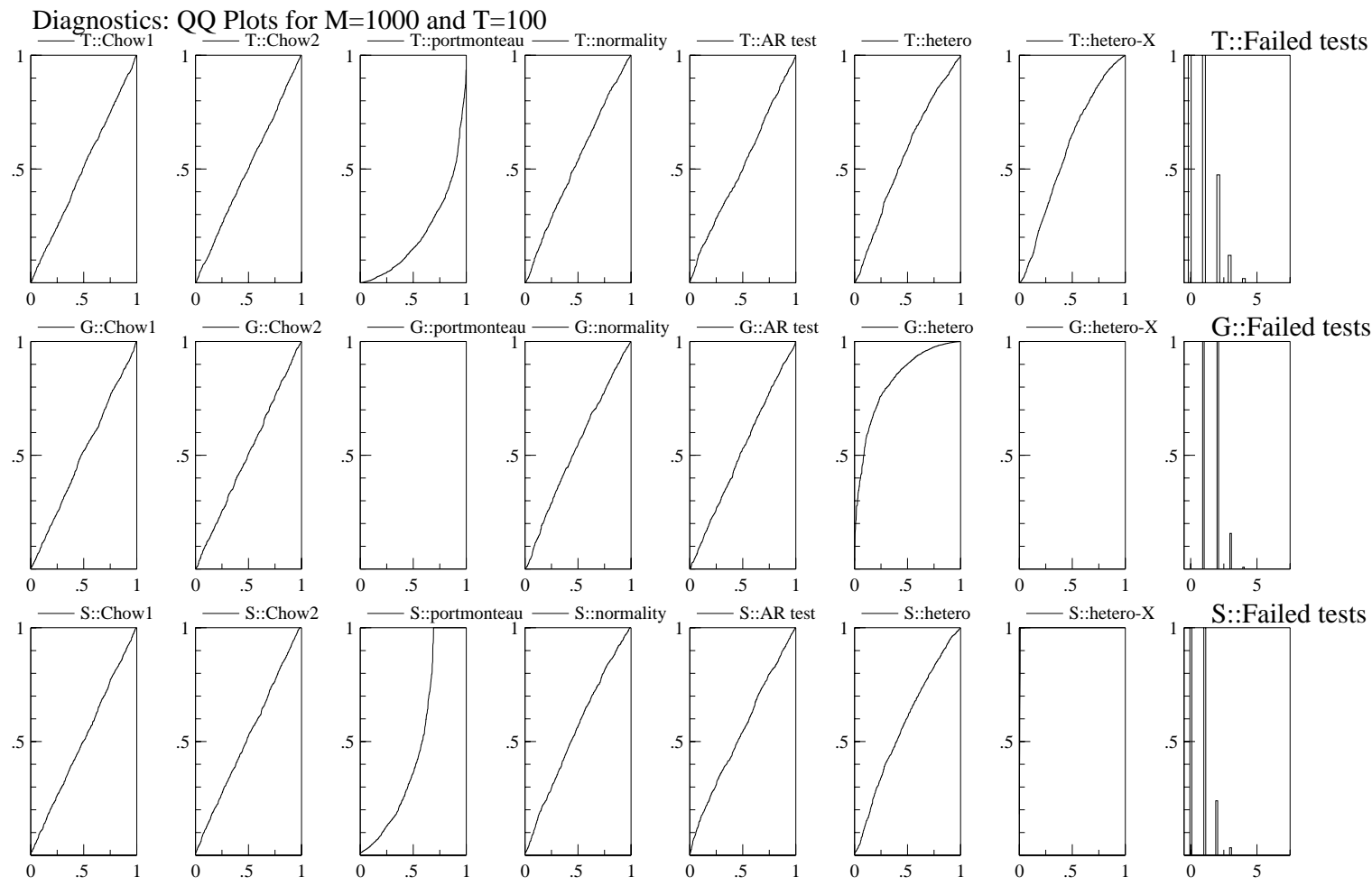

Figure 1 Selecting diagnostics.

Diagnostics: QQ Plots for $\mathrm{M}=1000$ and $\mathrm{T}=1000$
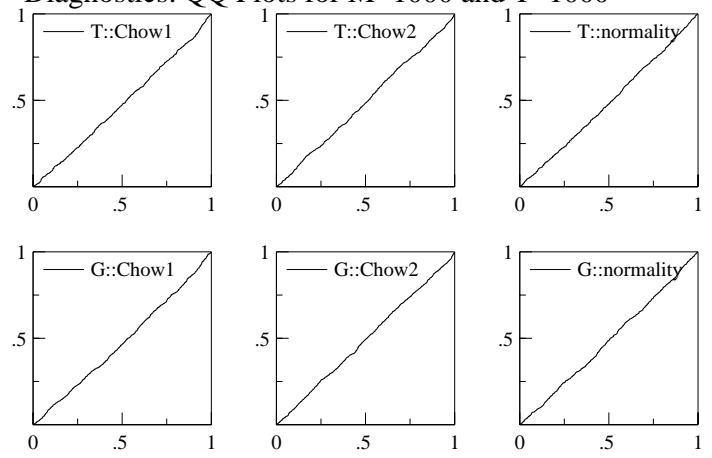

Diagnostics: QQ Plots for $\mathrm{M}=1000$ and $\mathrm{T}=100$
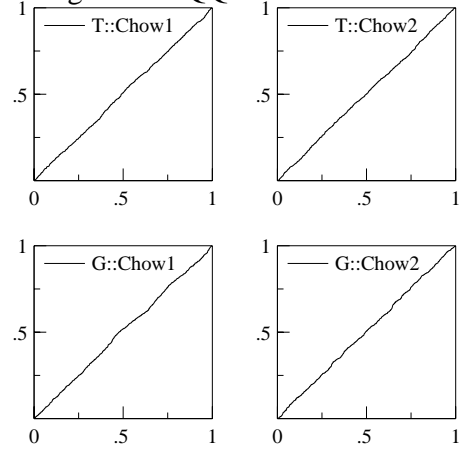
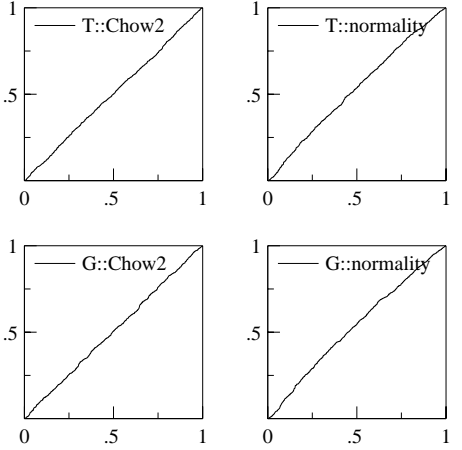
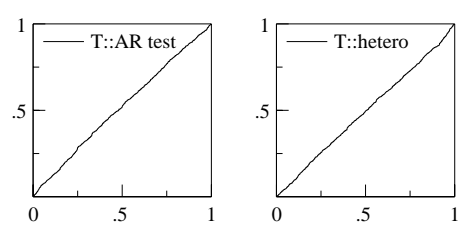

T::Failed tests
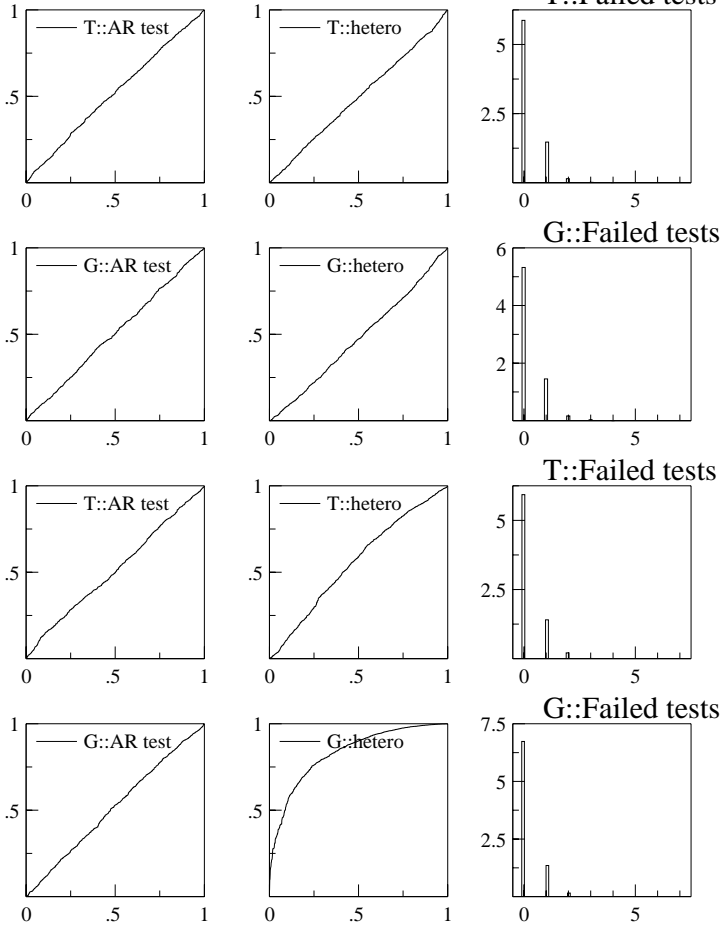

Figure 2 Diagnostics for small and large samples. 


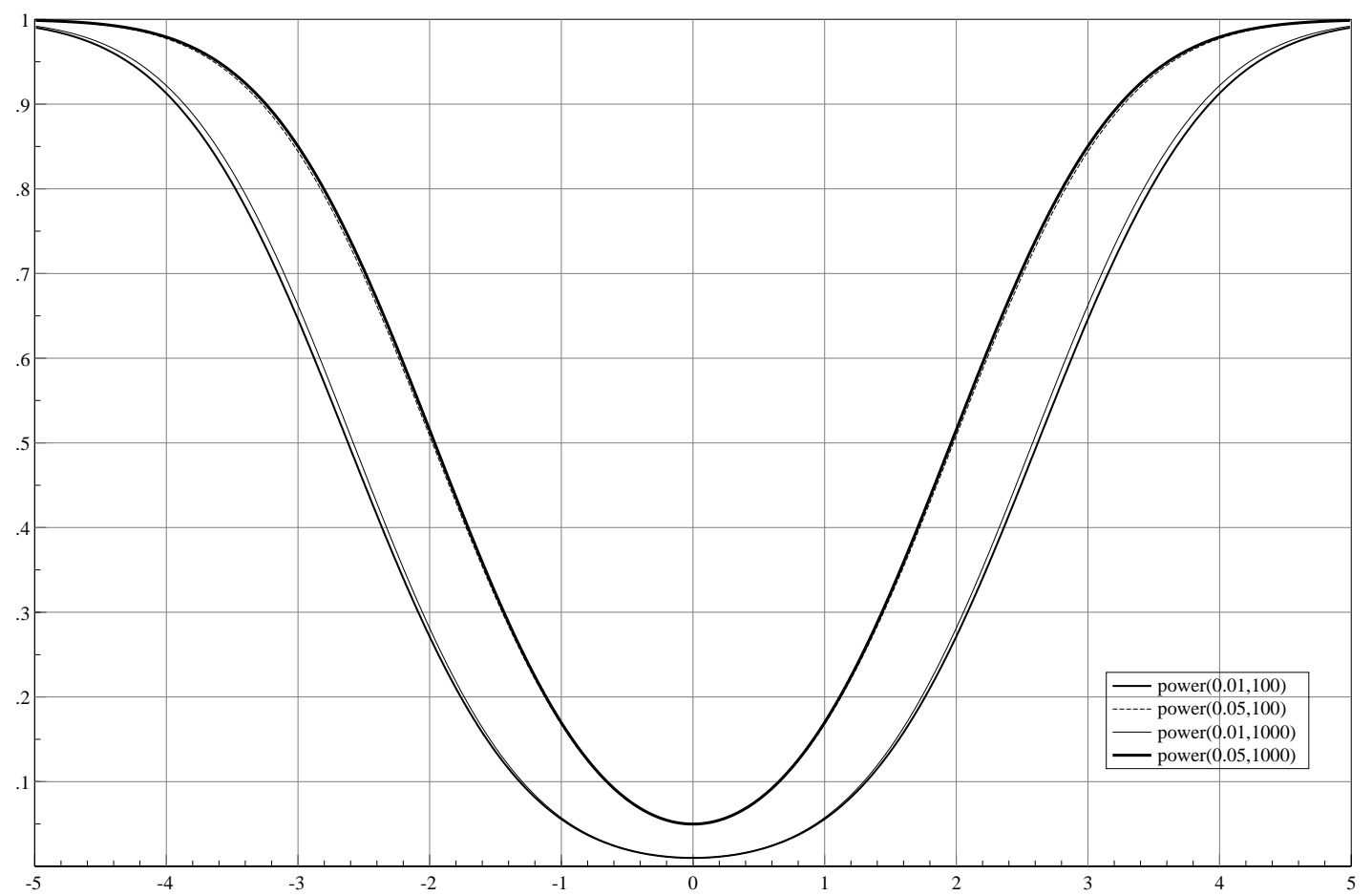

Figure 3 Power function of a t test for $\alpha=0.01$ and 0.05 , and $T=100$ and 1000 .

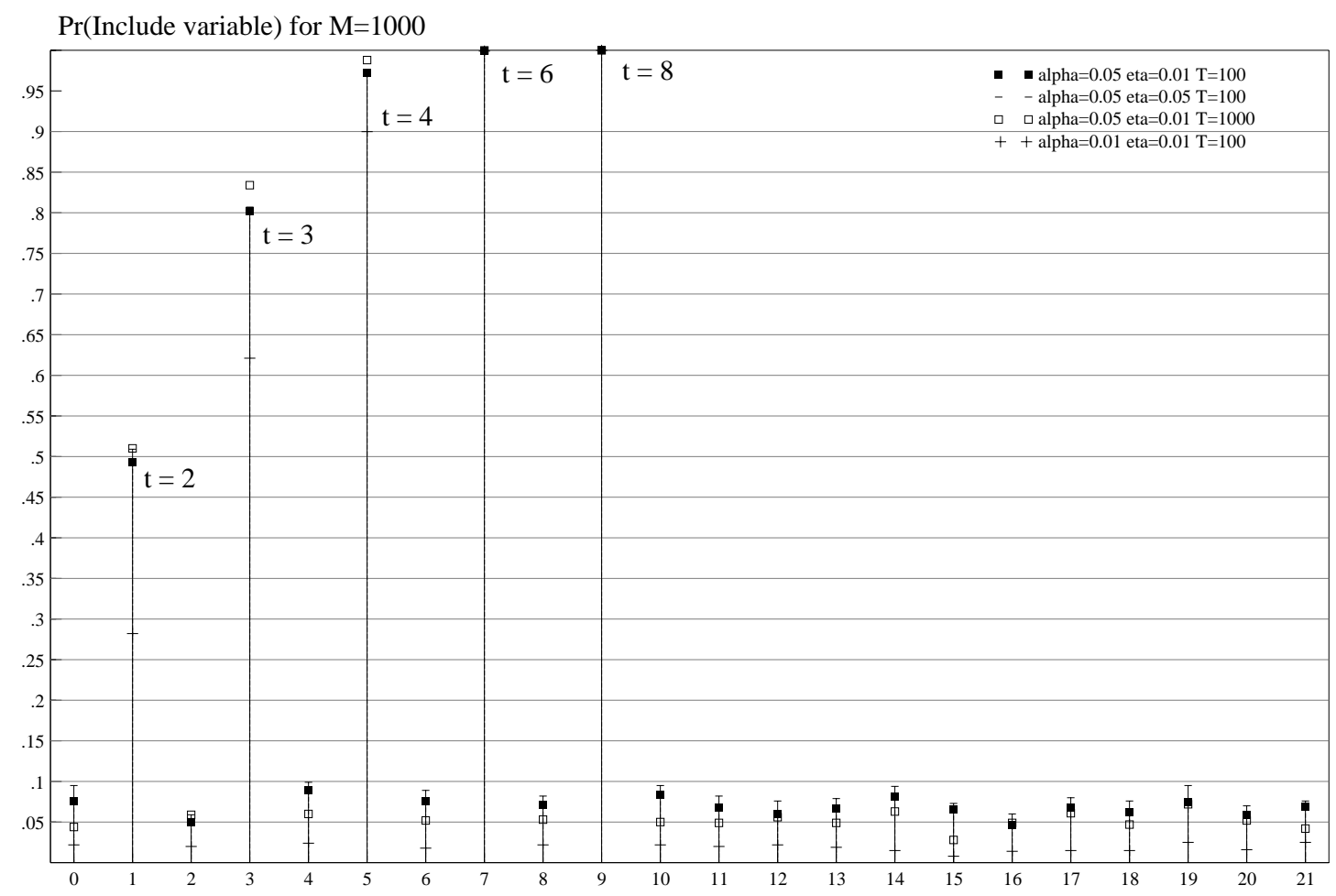

Figure 4 Probability of including each variable. 
For $\alpha=0.01$ and 0.05 , and $\nu=100$ and 1000, the power function is depicted in figure 3 .

Table 4 shows that for large samples $(T=1000)$, the size $(0.0521$ versus 0.05$)$ and power $(0.51$ versus 0.515 ) are nearly at the theoretical levels one would expect from a t-test of the true model. Hence the loss in size and power from the Gets model search is very much a small-sample feature. But even for 100 observations and 22 regressors, the results from PcGets are very promising. For $\alpha=\eta=0.01$, the loss in power is less than 0.025 and the size is 0.019 . The difference is smaller when compared to the empirical size and power. Note that we used the AIC when more than one model survived the model search and the encompassing process. Invoking the SC has little effect on the outcome, but helps to improve the size slightly. It is also worth noting that, in contrast to Hoover and Perez (1999), the results do not suggest that the algorithm is subject to a spurious overfitting. Figure 4 clarifies the 'success' and 'failure' of PcGets for the 22 regressors of the GUM (the coefficients are in the order of equation 1).

Smaller significance levels $(\alpha=0.01$ versus 0.05$)$ receive support from the size-power trade-offs. Changing the significance level of the t-tests reduces the empirical size accordingly, but lowers the power substantially for variables with population t-values of 2 or 3 , where the loss is about 0.20 . We found that $1 \%$ for all tests at the sample sizes current in macroeconomics does well, and dominates $5 \%$ dramatically on overall size, without much power loss for larger values of $t$.

\subsection{Test size analysis}

The MC reveals strong effects from the choice of the significance levels on the outcome of Gets. It is not only the significance level of the t-tests $(\alpha)$ that matters, but also those of the diagnostics $(\eta)$ : lowering the significance level of the diagnostic tests from 0.05 to 0.01 reduces the size by 0.01 without affecting the power. This is a striking effect which merits a closer examination.

It is important to distinguish between the individual significance levels $(\eta)$, and the overall significance level of the test battery - which can be difficult to determine. Suppose we have a battery of $n$ mis-specification tests each evaluated at the significance level $\eta$. Assuming independence of the tests, the overall rejection probability under the null is given by:

$$
1-(1-\eta)^{n}
$$

For example if $n=5$ and $\eta=0.05$, then the probability of rejecting the DGP is 0.2262 , which is substantial. To ensure an overall rejection probability of 0.05 under the null, the individual significance level $\eta$ has to satisfy $(1-\eta)^{n}=0.95$. For, say, $n=5$ mis-specification tests, then $\eta \simeq 0.01$ is necessary.

The combined variable-selection and specification-testing approach implies that the significance levels, $\eta$, of the diagnostics also affect the deletion probabilities for any non-DGP variable. The probability of selecting a non-DGP variable must be higher than the nominal size $\alpha$, since for pure random sampling, excluding even a nuisance variable can change the outcome of one or more diagnostic tests to a rejection. Thus, despite an insignificant t-statistic, PcGets would keep such a variable in the model.

The joint issue of variable selection and diagnostic testing in PcGets eludes most attempts at theoretical analysis. Consider therefore the following one-step reduction from a GUM denoted $\mathrm{M}_{1}$ to the DGP $\mathrm{M}_{2}$ :

$$
\begin{gathered}
\mathrm{M}_{1}(\mathrm{GUM}): y_{t}=\mathbf{x}_{t}^{\prime} \boldsymbol{\beta}_{1}+\mathbf{z}_{t}^{\prime} \boldsymbol{\beta}_{2}+u_{t}, \\
\mathrm{M}_{2}(\mathrm{DGP}): y_{t}=\mathbf{x}_{t}^{\prime} \boldsymbol{\theta}+\varepsilon_{t},
\end{gathered}
$$

where $\varepsilon_{t}$ is an innovation process. The reduction step consists of the specification test for $\boldsymbol{\beta}_{2}=\mathbf{0}$ ( $\mathrm{t}$ for scalar $\mathbf{z}_{t}$ or $\mathrm{F}$ for the vector case) and a set of $n$ mis-specification (diagnostic) tests. The significance levels are $\alpha$ and $\eta$, respectively: we assume that the tests are independent. 
Let $\mathcal{R}_{\mathrm{M}}\left(\overline{\mathcal{R}}_{\mathrm{M}}\right)$ denote a (non-)rejection on the set of diagnostic tests of model M. For the DGP $\left(\mathrm{M}_{2}\right)$, we have that

$$
\operatorname{Pr}\left(\overline{\mathcal{R}}_{\mathrm{M}_{2}}\right)=(1-\eta)^{n}=1-\operatorname{Pr}\left(\mathcal{R}_{\mathrm{M}_{2}}\right)
$$

Then the overall size $\alpha^{*}$ (the probability of a non-reduction) is given by

$$
\alpha+(1-\alpha) \operatorname{Pr}\left(\mathcal{R}_{\mathrm{M}_{2}}, \overline{\mathcal{R}}_{\mathrm{M}_{1}}\right)
$$

where the second term gives the inflation of the nominal size $\alpha$ due to the diagnostic testing, and:

$$
\begin{aligned}
\operatorname{Pr}\left(\mathcal{R}_{\mathrm{M}_{2}}, \overline{\mathcal{R}}_{\mathrm{M}_{1}}\right) & =\operatorname{Pr}\left(\mathcal{R}_{\mathrm{M}_{2}}\right) \operatorname{Pr}\left(\overline{\mathcal{R}}_{\mathrm{M}_{1}} \mid \mathcal{R}_{\mathrm{M}_{2}}\right) \\
& =\left[1-(1-\eta)^{n}\right] \phi(\eta, n) .
\end{aligned}
$$

The first term follows from the definition of the size of the test and independence. Under this condition, the second term can be written as $(1-\psi(\eta))^{n}$ where $\psi(\eta)$ is the probability of rejecting on a diagnostic test based on $M_{1}$ given that the same test has been rejected for $M_{2}$. Thus, for a combined variableselection and specification-testing approach, the overall size is given by:

$$
\alpha^{*}=\alpha+(1-\alpha)\left[1-(1-\eta)^{n}\right](1-\psi(\eta))^{n}
$$

which allows us to deduce $\psi(\eta)$ as:

$$
\psi(\eta)=1-\left(\frac{\alpha^{*}-\alpha}{(1-\alpha)\left[1-(1-\eta)^{n}\right]}\right)^{\frac{1}{n}} .
$$

Equation (4) provides a lower bound for any model search procedure. For example, it does not take into account that DGP variables can be eliminated according to the outcome of the specification tests. It is more difficult to decide on the significance level of a sequence of $t$ tests than that of an $F$ test for the same set of variables. The multi-step, multi-path reduction process of PcGets makes an analytical assessment intractable, but we get insights from the findings of the Monte Carlo: the results presented in table 4 show that without diagnostic testing (i.e., $\eta=0$ ), the empirical size of PcGets is 0.065 at a nominal size of $5 \%$. Correcting (4) for these effects, gives estimates of $\psi(\eta)$ as 0.386 and 0.399 for $\eta=0.01$ and 0.05. Although Monte Carlo is always problem dependent, our findings cohere with the established theory: the additional checking does not increase size greatly so long as we control the overall size of the test battery ( 0.069 for $\eta=0.01$ versus 0.081 when $\eta=0.05$ ). For complicated dynamic models with non-Gaussian or autocorrelated regressors, a combined variable-selection and specification-testing approach might even reduce the size overall for the final selection.

\section{Empirical Illustrations}

In this section, we apply PcGets to two well-known macro-econometric models: Davidson, Hendry, Srba and Yeo (1978) and Hendry and Ericsson (1991b).

\subsection{DHSY}

We reconsider the single-equation equilibrium-correction model of Davidson et al. (1978) (DHSY), who proposed the following model of consumers' expenditure in the UK:

$$
\Delta_{4} \widehat{c}_{t}=-0.09(c-y)_{t-4}+0.48 \Delta_{4} y_{t}-0.23 \Delta_{1} \Delta_{4} y_{t}-0.12 \Delta_{4} p_{t}-0.31 \Delta_{1} \Delta_{4} p_{t}+0.006 \Delta_{4} D_{t}
$$


where $y_{t}$ denotes disposable income, $c_{t}$ is consumers' expenditures on non-durable goods and services, $p_{t}$ is the implicit deflator of $c_{t}$ (all in $\operatorname{logs}$ ), and $D$ is a dummy variable with the value unity in $68(i)$ and $73(i),-1$ in the following quarter, and zero otherwise.

We started with a GUM that generalizes (5) by allowing for 5 lags of all differenced variables, their equilibrium-correction term, and a constant. The results are summarized in table 5. All three final models are valid non-dominated reductions of the GUM, only differing slightly in their dynamic specification. Model 1 would be preferable if one applied the AIC criterion, model 2 in the case of HQ and SC. It is worth noting that introducing centered seasonal dummies into the general model eliminates model 3 from the set of final models, but otherwise results in identical models. This is surprising, as there are significant seasonal effects in the general model B. A comparison with the model chosen by DHSY shows the potential power of an automated general-to-specific model selection: PcGets detects ones that dominate DHSY's final selection. The DHSY results reflect their decision to delete the $\Delta c_{t-3}$ term, which possibly leads to an economically more sensible model.

The value of structuring the problem before specifying the GUM becomes obvious in table 6 where we try up to 5 lags of each for $c_{t}$ on $y_{t}, \Delta_{4} p_{t}$, and a constant to see what PcGets finds. In table 7, seasonals are added.

It might be reassuring to see how the power of an 'artificial intelligence' model-specification system is limited by the researcher's specification of the GUM. This is very much in line with the ideas presaged in section 2.4 . 
Table 7 DHSY 1959 (2) - 1975 (4) .

\begin{tabular}{|c|c|c|c|c|c|c|c|c|c|c|}
\hline & \multicolumn{2}{|c|}{ DHSY } & GUM 1 & GUM 2 & \multicolumn{2}{|c|}{$\begin{array}{c}\text { Final model } 1 \\
(G U M 1, G U M 2)\end{array}$} & \multicolumn{2}{|c|}{$\begin{array}{c}\text { Final model } 2 \\
(G U M 1, G U M 2)\end{array}$} & \multicolumn{2}{|c|}{$\begin{array}{c}\text { Final model } 3 \\
(\text { GUM1) }\end{array}$} \\
\hline & Coeff & $\mathrm{t}$-value & Coeff $t$-value & Coeff t-value & Coeff & $\mathrm{t}$-value & Coeff & t-value & Coeff & t-value \\
\hline$\Delta_{4} c_{t-1}$ & & & $\begin{array}{ll}0.0743 & 0.5011\end{array}$ & $0.0041 \quad 0.0273$ & & & & & & \\
\hline$\Delta_{4} c_{t-2}$ & & & $-0.0472-0.3502$ & $-0.0275-0.2069$ & & & & & & \\
\hline$\Delta_{4} c_{t-3}$ & & & $0.2304 \quad 1.7445$ & $0.2317 \quad 1.7767$ & 0.1743 & 3.0144 & 0.2572 & 3.7712 & 0.1706 & 2.7910 \\
\hline$\Delta_{4} c_{t-4}$ & & & $-0.0545-0.3959$ & $-0.0399-0.2939$ & & & & & & \\
\hline$\Delta_{4} c_{t-5}$ & & & 0.08210 .6450 & $-0.0045-0.0338$ & & & & & & \\
\hline$\overline{\Delta_{4} y_{t}}$ & 0.2508 & 7.0717 & 0.23325 .2662 & $0.2594 \quad 5.6941$ & 0.2486 & 7.5433 & 0.2614 & 8.1151 & 0.2362 & 6.8964 \\
\hline$\Delta_{4} y_{t-1}$ & 0.2300 & 5.7883 & $0.1618 \quad 2.5850$ & $0.1787 \quad 2.8231$ & 0.1891 & 4.8657 & 0.1505 & 4.3485 & 0.1874 & 4.7449 \\
\hline$\Delta_{4} y_{t-2}$ & & & $\begin{array}{lll}0.0267 & 0.4318\end{array}$ & $0.0353 \quad 0.5757$ & & & & & & \\
\hline$\Delta_{4} y_{t-3}$ & & & $-0.0226-0.3912$ & $-0.0261-0.4551$ & & & & & & \\
\hline$\Delta_{4} y_{t-4}$ & & & $\begin{array}{lll}0.0069 & 0.0938\end{array}$ & $-0.0265-0.3489$ & & & & & & \\
\hline$\Delta_{4} y_{t-5}$ & & & $-0.0300-0.4333$ & $-0.0130-0.1853$ & & & & & & \\
\hline$\Delta_{4} p_{t}$ & -0.4227 & -4.3869 & $-0.4309-3.3889$ & $-0.4339-3.4581$ & -0.4284 & -4.7064 & -0.2930 & -6.5579 & -0.3708 & -3.9073 \\
\hline$\Delta_{4} p_{t-1}$ & 0.3051 & 2.9585 & $0.2633 \quad 1.3715$ & $0.2170 \quad 1.1377$ & 0.2668 & 2.5528 & & & 0.2307 & 2.1328 \\
\hline$\Delta_{4} p_{t-2}$ & & & $-0.0210-0.1146$ & 0.03220 .1745 & & & & & & \\
\hline$\Delta_{4} p_{t-3}$ & & & $0.2005 \quad 1.0743$ & $0.1677 \quad 0.9034$ & & & 0.2490 & 3.9625 & & \\
\hline$\Delta_{4} p_{t-4}$ & & & $-0.2537-1.3480$ & $-0.2317-1.2414$ & & & & & & \\
\hline$\Delta_{4} p_{t-5}$ & & & $0.2110 \quad 1.4990$ & $0.1215 \quad 0.8370$ & 0.1150 & 2.3280 & & & 0.1250 & 2.5184 \\
\hline$(c-y)_{t-4}$ & -0.0930 & -7.7312 & $-0.0349-1.1461$ & $-0.1315-2.3522$ & -0.0591 & -3.9155 & -0.0504 & -3.0787 & & \\
\hline Constant & & & $0.0026 \quad 0.5100$ & $-0.0069-1.0139$ & & & & & 0.0087 & 3.6101 \\
\hline$\Delta_{4} D_{t}$ & 0.0065 & 2.8869 & $0.0083 \quad 2.7285$ & $0.0074 \quad 2.4178$ & 0.0063 & 3.0116 & 0.0068 & 3.2809 & 0.0060 & 2.8834 \\
\hline CSeason_1 & & & & 0.00852 .0815 & & & & & & \\
\hline CSeason_2 & & & & $0.0051 \quad 1.6312$ & & & & & & \\
\hline CSeason_3 & & & & $0.0043 \quad 1.5988$ & & & & & & \\
\hline$\overline{\mathrm{RSS}}$ & & $\overline{0.0023}$ & $\overline{0.0018}$ & $\overline{0.0016}$ & & 0.0019 & & $\overline{0.0020}$ & & $\overline{0.0020}$ \\
\hline sigma & & 0.0062 & 0.0062 & 0.0061 & & 0.0057 & & 0.0058 & & 0.0058 \\
\hline $\mathrm{R}^{2}$ & & 0.8528 & 0.8867 & 0.8970 & & 0.8770 & & 0.8720 & & 0.8731 \\
\hline $\mathbf{R}_{a d j}^{2}$ & & 0.7764 & 0.6220 & 0.5891 & & 0.7723 & & 0.7809 & & 0.7688 \\
\hline LogLik & & 344.0657 & 352.8531 & 356.0237 & & 350.0929 & & 48.7563 & & 349.0408 \\
\hline AIC & & -10.0915 & -9.9359 & -9.9410 & & -10.2117 & & -10.2017 & & -10.1803 \\
\hline HQ & & -10.0134 & -9.6755 & -9.6415 & & -10.1076 & & -10.1105 & & -10.0762 \\
\hline $\mathrm{SC}$ & & -9.8941 & -9.2778 & -9.1842 & & -9.9485 & & -9.9713 & & -9.9171 \\
\hline Chow(1967:4) & 1.0142 & 0.4887 & $0.9630 \quad 0.5573$ & $\begin{array}{lll}0.7620 & 0.7388\end{array}$ & 0.8585 & 0.6641 & 0.8551 & 0.6687 & 0.9570 & 0.5527 \\
\hline Chow(1973:4) & 0.7281 & 0.6945 & $\begin{array}{lll}0.7187 & 0.7017\end{array}$ & 0.47180 .8966 & 0.6256 & 0.7847 & 0.7414 & 0.6824 & 0.7863 & 0.6417 \\
\hline normality test & 0.1120 & 0.9455 & $\begin{array}{lll}0.6559 & 0.7204\end{array}$ & $0.0374 \quad 0.9815$ & 0.5170 & 0.7722 & 0.8055 & 0.6685 & 1.4087 & 0.4944 \\
\hline AR $1-5$ test & 0.2239 & 0.9507 & $0.3498 \quad 0.8795$ & $0.4442 \quad 0.8148$ & 0.1000 & 0.9917 & 0.3536 & 0.8778 & 0.4999 & 0.7750 \\
\hline hetero test & 0.6478 & 0.7906 & $\begin{array}{ll}0.3855 & 0.9772\end{array}$ & $0.1980 \quad 0.9891$ & 0.6231 & 0.8469 & 0.6810 & 0.7801 & 0.4172 & 0.9611 \\
\hline
\end{tabular}

(1) DHSY corresponds to equation (8.45)** in Davidson et al. (1978).

(2) $\Delta_{4} D_{t}$ is the fourth difference of a dummy variable which is $+1,-1$ in 1968(i), 1968(ii) and 1973(i),1973(ii) reflecting budget effects in 1968 and the introduction of VAT in 1973 (see footnote 5 in Davidson et al., 1978)

(3) CSeason_1,2,3 are centralised seasonal dummies. 
Table 8 DHSY without SEASONALS, 1959 (2) - 1976 (2) .

\begin{tabular}{|c|c|c|c|c|c|c|c|c|c|c|}
\hline & \multicolumn{2}{|c|}{ General model } & \multicolumn{2}{|c|}{ Final model 1} & \multicolumn{2}{|c|}{ Final model 2} & \multicolumn{2}{|c|}{ Final model 3} & \multicolumn{2}{|c|}{ Final model 4} \\
\hline & Coeff & t-value & Coeff & t-value & Coeff & t-value & Coeff & t-value & Coeff & t-value \\
\hline$\Delta_{4} c_{t-1}$ & -0.0900 & -0.6248 & & & & & & & & \\
\hline$\Delta_{4} c_{t-2}$ & -0.0377 & -0.2660 & & & & & & & & \\
\hline$\Delta_{4} c_{t-3}$ & 0.2406 & 1.7255 & 0.2554 & 3.1972 & 0.1471 & 2.4153 & 0.1871 & 2.7581 & 0.1524 & 2.3475 \\
\hline$\Delta_{4} c_{t-4}$ & -0.0079 & -0.0551 & & & & & & & & \\
\hline$\Delta_{4} c_{t-5}$ & 0.0395 & 0.2943 & & & & & & & & \\
\hline$\Delta_{4} y_{t}$ & 0.2489 & 5.3523 & 0.2630 & 7.5598 & 0.2762 & 7.8876 & 0.2859 & 8.2106 & 0.2738 & 7.8156 \\
\hline$\Delta_{4} y_{t-1}$ & 0.2030 & 3.1752 & 0.1896 & 4.8375 & 0.1879 & 4.6804 & 0.1585 & 4.1983 & 0.1346 & 3.7473 \\
\hline$\Delta_{4} y_{t-2}$ & 0.0540 & 0.8294 & & & & & & & & \\
\hline$\Delta_{4} y_{t-3}$ & -0.0064 & -0.1074 & & & & & & & & \\
\hline$\Delta_{4} y_{t-4}$ & -0.0934 & -1.3259 & -0.0804 & -2.0297 & & & & & & \\
\hline$\Delta_{4} y_{t-5}$ & 0.0186 & 0.2645 & & & & & & & & \\
\hline$\Delta_{4} p_{t}$ & -0.3919 & -3.0655 & -0.3999 & -5.0674 & -0.3919 & -4.8537 & -0.2742 & -5.3097 & -0.1693 & -5.8668 \\
\hline$\Delta_{4} p_{t-1}$ & 0.2399 & 1.1928 & 0.3032 & 3.6100 & 0.2868 & 3.3490 & & & & \\
\hline$\Delta_{4} p_{t-2}$ & 0.0186 & 0.0958 & & & & & 0.1829 & 3.0574 & 0.1829 & 3.0574 \\
\hline$\Delta_{4} p_{t-3}$ & 0.0601 & 0.3192 & & & & & & & & \\
\hline$\Delta_{4} p_{t-4}$ & -0.2125 & -1.0761 & & & & & & & & \\
\hline$\Delta_{4} p_{t-5}$ & 0.2154 & 1.4561 & & & & & & & 0.1427 & 3.3997 \\
\hline$(c-y)_{t-4}$ & -0.0514 & -1.6258 & -0.0696 & -4.6275 & -0.0699 & -4.5376 & -0.0643 & -3.8717 & -0.0643 & -3.8717 \\
\hline Constant & 0.0033 & 0.6162 & & & & & & & 0.0099 & 3.9229 \\
\hline RSS & & 0.0022 & & 0.0023 & & 0.0025 & & 0.0026 & & 0.0025 \\
\hline sigma & & 0.0066 & & 0.0061 & & 0.0063 & & 0.0064 & & 0.0063 \\
\hline $\mathrm{R}^{2}$ & & 0.8804 & & 0.8705 & & 0.8619 & & 0.8583 & & 0.8626 \\
\hline $\operatorname{Radj}^{2}$ & & 0.6380 & & 0.7822 & & 0.7869 & & 0.7837 & & 0.7876 \\
\hline LogLik & & 357.8109 & & 355.0706 & & 352.8512 & & 351.9716 & & 353.0330 \\
\hline AIC & & -9.8206 & & -10.0890 & & -10.0537 & & -10.0282 & & -10.0589 \\
\hline HQ & & -9.5765 & & -9.9991 & & -9.9766 & & -9.9511 & & -9.9819 \\
\hline $\mathrm{SC}$ & & -9.2054 & & -9.8624 & & -9.8594 & & -9.8339 & & -9.8647 \\
\hline Chow(1967:4) & 1.3920 & 0.2434 & 1.1658 & 0.3414 & 1.1699 & 0.3354 & 1.0505 & 0.4494 & 1.3654 & 0.1978 \\
\hline Chow(1973:4) & 0.9134 & 0.5305 & 0.6604 & 0.7551 & 0.7546 & 0.6706 & 0.8571 & 0.5776 & 0.8929 & 0.5459 \\
\hline normality test & 0.2589 & 0.8786 & 0.3234 & 0.8507 & 0.0989 & 0.9517 & 0.4123 & 0.8137 & 0.3682 & 0.8319 \\
\hline AR $1-5$ test & 0.2791 & 0.9222 & 0.2078 & 0.9579 & 0.2303 & 0.9478 & 0.2538 & 0.9362 & 0.4904 & 0.7821 \\
\hline hetero test & 0.2646 & 0.9992 & 0.6009 & 0.8505 & 0.7030 & 0.7409 & 0.7415 & 0.7047 & 0.4176 & 0.9318 \\
\hline
\end{tabular}


Table 9 DHSY with SEASONALS, 1959 (2) - 1976 (2) .

\begin{tabular}{|c|c|c|c|c|c|c|c|c|}
\hline & \multicolumn{2}{|c|}{ General model } & \multicolumn{2}{|c|}{ Final model 1} & \multicolumn{2}{|c|}{ Final model 2} & \multicolumn{2}{|c|}{ Final model 3} \\
\hline & Coeff & $\mathrm{t}$-value & Coeff & t-value & Coeff & $\mathrm{t}$-value & Coeff & $t$-value \\
\hline$\Delta_{4} c_{t-1}$ & -0.1582 & -1.1301 & & & & & & \\
\hline$\Delta_{4} c_{t-2}$ & -0.0260 & -0.1915 & & & & & & \\
\hline$\Delta_{4} c_{t-3}$ & 0.2234 & 1.6707 & 0.2256 & 2.8686 & 0.2539 & 2.9652 & 0.1315 & 2.0653 \\
\hline$\Delta_{4} c_{t-4}$ & 0.0117 & 0.0851 & & & & & & \\
\hline$\Delta_{4} c_{t-5}$ & -0.0609 & -0.4550 & & & & & & \\
\hline$\Delta_{4} y_{t}$ & 0.2726 & 5.9369 & 0.2587 & 7.6527 & 0.2694 & 7.9734 & 0.2888 & 8.7700 \\
\hline$\Delta_{4} y_{t-1}$ & 0.2221 & 3.5704 & 0.1839 & 4.8264 & 0.1555 & 4.3204 & 0.1331 & 3.7959 \\
\hline$\Delta_{4} y_{t-2}$ & 0.0588 & 0.9378 & & & & & & \\
\hline$\Delta_{4} y_{t-3}$ & -0.0047 & -0.0831 & & & & & & \\
\hline$\Delta_{4} y_{t-4}$ & -0.1178 & -1.7262 & -0.0836 & -2.1744 & -0.0801 & -2.0466 & & \\
\hline$\Delta_{4} y_{t-5}$ & 0.0426 & 0.6174 & & & & & & \\
\hline$\Delta_{4} p_{t}$ & -0.4303 & -3.4959 & -0.3794 & -4.9201 & -0.2646 & -5.3552 & -0.2035 & -7.0134 \\
\hline$\Delta_{4} p_{t-1}$ & 0.2027 & 1.0457 & 0.2661 & 3.1994 & & & & \\
\hline$\Delta_{4} p_{t-2}$ & 0.0557 & 0.2932 & & & 0.1622 & 2.7605 & & \\
\hline$\Delta_{4} p_{t-3}$ & 0.0612 & 0.3375 & & & & & & \\
\hline$\Delta_{4} p_{t-4}$ & -0.1809 & -0.9521 & & & & & & \\
\hline$\Delta_{4} p_{t-5}$ & 0.1200 & 0.8230 & & & & & 0.1244 & 2.9540 \\
\hline$(c-y)_{t-4}$ & -0.1711 & -3.2051 & -0.0827 & -5.2521 & -0.0784 & -4.5545 & -0.0765 & -4.4559 \\
\hline Constant & -0.0092 & -1.3280 & & & & & & \\
\hline CSeason_1 & 0.0107 & 2.7376 & 0.0039 & 2.2111 & 0.0039 & 2.1400 & 0.0039 & 2.1593 \\
\hline CSeason_2 & 0.0065 & 2.0817 & & & & & & \\
\hline CSeason_3 & 0.0046 & 1.6746 & & & & & & \\
\hline RSS & & 0.0019 & & 0.0022 & & 0.0022 & & 0.0023 \\
\hline sigma & & 0.0063 & & 0.0060 & & 0.0061 & & 0.0061 \\
\hline $\mathrm{R}^{2}$ & & 0.8972 & & 0.8801 & & 0.8755 & & 0.8710 \\
\hline $\operatorname{Radj}^{2}$ & & 0.6111 & & 0.7781 & & 0.7740 & & 0.7826 \\
\hline LogLik & & 363.0433 & & 357.7306 & & 356.4398 & & 355.2075 \\
\hline AIC & & -9.8853 & & -10.1371 & & -10.0997 & & -10.0930 \\
\hline HQ & & -9.6027 & & -10.0344 & & -9.9969 & & -10.0031 \\
\hline $\mathrm{SC}$ & & -9.1730 & & -9.8781 & & -9.8407 & & -9.8663 \\
\hline Chow(1967:4) & 1.0230 & 0.5082 & 1.0827 & 0.4201 & 1.1253 & 0.3797 & 1.1338 & 0.3697 \\
\hline Chow(1973:4) & 0.5628 & 0.8330 & 0.5121 & 0.8736 & 0.5742 & 0.8272 & 0.8614 & 0.5739 \\
\hline normality test & 0.0787 & 0.9614 & 0.4538 & 0.7970 & 0.7825 & 0.6762 & 0.6811 & 0.7114 \\
\hline AR $1-5$ test & 1.2453 & 0.3054 & 0.1856 & 0.9669 & 0.2376 & 0.9442 & 0.4448 & 0.8153 \\
\hline hetero test & 0.1703 & 0.9999 & 0.6109 & 0.8504 & 0.7793 & 0.6924 & 0.8515 & 0.6062 \\
\hline
\end{tabular}




\subsection{UK Money Demand}

We now reconsider the Hendry and Ericsson (1991b) model (HE) of narrow money demand in the UK:

$$
\Delta(\widehat{m-p})_{t}=-0.093(m-p-x)_{t-1}-0.17 \Delta(m-p-x)_{t-1}-0.69 \Delta p_{t}-0.63 R_{t}+0.023
$$

where the lower-case data are in logs: $m$ is M1, $x$ is real total final expenditure in 1985 prices, $p$ is its deflator, and $R$ is the opportunity cost of holding money (3-month local-authority interest rate minus the retail sight-deposit rate). The results using PcGets are given in table 9.

Two GUMs are considered, both nesting (6) without imposing the homogeneity restriction for $\Delta(m-p)$ and $\Delta x$. As the GUMs A and B are linked by linear transformations of the same set of regressors leading to an identical fit, A and B are observationally equivalent. Although transformations per se do not entail any associated reduction, the different structuring of the information set affects the reduction process. This highlights the role of variable orthogonalization.

Just one model survived the selection process in each case. Final model A corresponds to the HE model without imposing the homogeneity restriction and, hence, leaves a further valid reduction: the $\Delta x_{t-1}$ coefficient is dropped by $P c G e t s$ after acceptance by the corresponding t-test (also supported by HQ and SC). The final model resulting from the GUM B is also essentially the HE model as:

$$
\begin{aligned}
-0.8 \Delta^{2} p_{t}-0.7 \Delta p_{t-1} & =-0.8 \Delta p_{t}+0.8 \Delta p_{t-1}-0.7 \Delta p_{t-1} \\
& =-0.8 \Delta p_{t}+0.1 \Delta p_{t-1},
\end{aligned}
$$

and the last term is irrelevant. But only an 'expert system' would notice the link between the regressors to cancel the redundant term. However, the initial formulation of regressors clearly matters, supporting EqCM forms, and confirming that orthogonalization seems to help. Alternatively, if the cointegration vector is used:

$$
(m-p-x)_{t-1}-7 \Delta p_{t-1}-0.7 R_{t-1},
$$

then both $\Delta^{2} p$ and $\Delta R$ enter (see Doornik and Hendry, 1992), so that is also a correct feature detected. PcGets seems to be doing remarkably well as an expert on the empirical problems, as well as mimicking the good size and power properties Hoover and Perez (1999) claim.

To illustrate the benefits from structuring the problem, we consider a simple unrestricted autoregressive-distributed lag model for UK M1, regressing $m$ on $p, x$, and $R$ with a lag length of 4. As shown in table 8 , three reduced models survive the model-selection process, and differ regarding their dynamic specification, but are close regarding their long-run effects. Model 1 uniformly dominates 2 and 3. When rewritten in an equilibrium-correction form, the selected outcome is again similar to HE:

$$
\begin{aligned}
\Delta m_{t} & =-0.33 m_{t-1}+0.21 m_{t-4}+0.33 p_{t}-0.20 p_{t-3}+0.13 x_{t}-0.58 R_{t}-0.34 R_{t-2} \\
& \simeq-0.11(m-p-x)_{t-1}-0.21 \Delta_{3} m_{t-1}+0.20 \Delta_{3} p_{t}+0.11 \Delta x_{t}-0.92 R_{t}+0.34 \Delta_{2} R_{t}(.7)
\end{aligned}
$$

If pre-search F-tests are used (at 10\%), the final model is the same as (7) other than omitting $R_{t-2}$. It remains to stress that these cases benefit from 'fore-knowledge' (e.g., of dummies, lag length etc.), some of which took the initial investigators time to find. 
Table 10 UKM1 Money Demand, 1964 (1) - 1989 (2).

\begin{tabular}{|c|c|c|c|c|c|c|c|c|c|c|c|c|}
\hline & \multicolumn{2}{|c|}{$\mathrm{HE}$} & \multicolumn{2}{|c|}{ Unrestricted HE } & \multicolumn{2}{|c|}{ General A } & \multicolumn{2}{|c|}{ Final model A } & \multicolumn{2}{|c|}{ General B } & \multicolumn{2}{|c|}{ Final model B } \\
\hline & Coeff & t-value & Coeff & t-value & Coeff & t-value & Coeff & t-value & Coeff & t-value & Coeff & t-value \\
\hline$(m-p-x)_{t-1}$ & -0.0928 & -10.8734 & $\begin{array}{l}-0.0938 \\
\end{array}$ & -10.6160 & $\begin{array}{l}-0.1584 \\
\end{array}$ & -6.0936 & $\begin{array}{l}-0.0934 \\
\end{array}$ & -10.5108 & $\begin{array}{l}-0.1584 \\
\end{array}$ & -6.0936 & -0.1035 & -9.1048 \\
\hline $\begin{array}{l}\Delta p_{t} \\
\Delta p_{t-1}\end{array}$ & -0.6870 & -5.4783 & -0.6952 & -5.4693 & -1.0499 & -4.8670 & -0.7005 & -5.4831 & -1.0499 & -4.8670 & -0.7021 & -4.8215 \\
\hline $\begin{array}{l}r_{t} \\
r_{t-1}\end{array}$ & -0.6296 & -10.4641 & -0.6411 & -9.8391 & -1.1121 & -6.1012 & -0.6468 & -9.8893 & -1.1121 & -6.1012 & -0.7223 & -9.2106 \\
\hline $\begin{array}{c}\Delta(m-p)_{t-1} \\
\Delta(m-p)_{t-2} \\
\Delta(m-p)_{t-3} \\
\Delta(m-p)_{t-4}\end{array}$ & -0.1746 & -3.0102 & -0.1926 & -2.7637 & $\begin{array}{l}-0.2827 \\
-0.0407 \\
-0.2906 \\
-0.1446\end{array}$ & $\begin{array}{l}-2.7449 \\
-0.3696 \\
-2.6800 \\
-1.3519\end{array}$ & -0.1858 & -2.6569 & $\begin{array}{l}-0.2827 \\
-0.0407 \\
-0.2906 \\
-0.1446\end{array}$ & $\begin{array}{l}-2.7449 \\
-0.3696 \\
-2.6800 \\
-1.3519\end{array}$ & -0.2520 & -2.7609 \\
\hline $\begin{array}{l}\Delta x_{t} \\
\Delta x_{t-1} \\
\Delta x_{t-2} \\
\Delta x_{t-3} \\
\Delta x_{t-4}\end{array}$ & 0.1746 & 3.0102 & 0.1384 & 1.4392 & $\begin{array}{r}-0.0623 \\
0.0718 \\
0.0083 \\
-0.2274 \\
-0.0925\end{array}$ & $\begin{array}{r}-0.5509 \\
0.5870 \\
0.0720 \\
-1.8802 \\
-0.7815\end{array}$ & & & $\begin{array}{r}-0.0623 \\
0.0718 \\
0.0083 \\
-0.2274 \\
-0.0925\end{array}$ & $\begin{array}{r}-0.5509 \\
0.5870 \\
0.0720 \\
-1.8802 \\
-0.7815\end{array}$ & & \\
\hline $\begin{array}{l}\Delta r_{t} \\
\Delta r_{t-1} \\
\Delta r_{t-2} \\
\Delta r_{t-3} \\
\Delta r_{t-4}\end{array}$ & & & & & $\begin{array}{l}0.6884 \\
0.3293 \\
0.2038 \\
0.1631 \\
0.0872\end{array}$ & $\begin{array}{l}3.1647 \\
1.7151 \\
1.2647 \\
1.1558 \\
0.7119\end{array}$ & & & $\begin{array}{r}-0.4236 \\
0.3293 \\
0.2038 \\
0.1631 \\
0.0872\end{array}$ & $\begin{array}{r}-3.6397 \\
1.7151 \\
1.2647 \\
1.1558 \\
0.7119\end{array}$ & -0.4842 & -4.5733 \\
\hline Constant & 0.0234 & 5.8186 & 0.0244 & 5.3756 & 0.0434 & 5.1072 & 0.0262 & 5.9862 & 0.0434 & 5.1072 & 0.0276 & 6.1696 \\
\hline $\begin{array}{l}\text { RSS } \\
\text { sigma } \\
\mathrm{R}^{2} \\
\text { Radj }^{2} \\
\text { LogLik } \\
\text { AIC } \\
\text { HQ } \\
\text { SC } \\
\end{array}$ & & $\begin{array}{r}0.0164 \\
0.0131 \\
0.7616 \\
0.7235 \\
435.8552 \\
-8.6171 \\
-8.5644 \\
-8.4868 \\
\end{array}$ & & $\begin{array}{r}0.0163 \\
0.0132 \\
0.7622 \\
0.7165 \\
435.9734 \\
-8.5995 \\
-8.5362 \\
-8.4432 \\
\end{array}$ & & $\begin{array}{r}0.0130 \\
0.0130 \\
0.8103 \\
0.6240 \\
447.2861 \\
-8.4857 \\
-8.2432 \\
-7.8865 \\
\end{array}$ & & $\begin{array}{r}0.0167 \\
0.0133 \\
0.7569 \\
0.7191 \\
434.8837 \\
-8.5977 \\
-8.5450 \\
-8.4674 \\
\end{array}$ & & $\begin{array}{r}0.0130 \\
0.0130 \\
0.8103 \\
0.6240 \\
447.2861 \\
-8.4857 \\
-8.2432 \\
-7.8865 \\
\end{array}$ & & $\begin{array}{r}0.0160 \\
0.0131 \\
0.7664 \\
0.7128 \\
436.8711 \\
-8.5974 \\
-8.5236 \\
-8.4151 \\
\end{array}$ \\
\hline
\end{tabular}


Table 11 UKM1 Money Demand, 1964 (1) - 1989 (2).

\begin{tabular}{|c|c|c|c|c|c|c|c|c|}
\hline & \multicolumn{2}{|c|}{ General model } & \multicolumn{2}{|c|}{ Final model 1} & \multicolumn{2}{|c|}{ Final model 2} & \multicolumn{2}{|c|}{ Final model 3} \\
\hline & Coeff & $\mathrm{t}$-value & Coeff & $t$-value & Coeff & t-value & Coeff & t-value \\
\hline$m_{t-1}$ & 0.6265 & 5.8463 & 0.6661 & 9.3474 & 0.6963 & 9.9698 & 0.6309 & 6.4812 \\
\hline$m_{t-2}$ & 0.1744 & 1.4059 & & & & & 0.2708 & 2.9985 \\
\hline$m_{t-3}$ & -0.2084 & -1.6438 & & & & & & \\
\hline$m_{t-4}$ & 0.2815 & 2.7652 & 0.2083 & 3.5952 & 0.1847 & 3.2485 & & \\
\hline$p_{t}$ & 0.1466 & 0.6854 & 0.3322 & 5.9563 & & & & \\
\hline$p_{t-1}$ & 0.3099 & 0.8998 & & & 0.4484 & 5.7072 & 0.3868 & 5.4743 \\
\hline$p_{t-2}$ & -0.0557 & -0.1613 & & & & & & \\
\hline$p_{t-3}$ & -0.4272 & -1.2779 & -0.2049 & -4.0702 & -0.3278 & -4.4808 & -0.2880 & -4.1340 \\
\hline$p_{t-4}$ & 0.1470 & 0.7631 & & & & & & \\
\hline$x_{t}$ & -0.0140 & -0.1297 & 0.1290 & 6.6776 & & & & \\
\hline$x_{t-1}$ & 0.2946 & 2.2751 & & & 0.1222 & 6.3752 & 0.1008 & 6.6021 \\
\hline$x_{t-2}$ & -0.1351 & -1.0353 & & & & & & \\
\hline$x_{t-3}$ & -0.1585 & -1.2075 & & & & & & \\
\hline$x_{t-4}$ & 0.1693 & 1.5595 & & & & & & \\
\hline$r_{t}$ & -0.4164 & -3.6849 & -0.5812 & -8.6121 & -0.5219 & -7.9668 & -0.4217 & -4.4029 \\
\hline$r_{t-1}$ & -0.3253 & -1.9202 & & & & & -0.2880 & -2.3268 \\
\hline$r_{t-2}$ & -0.0726 & -0.4207 & -0.3380 & -3.0200 & -0.3400 & -2.9697 & & \\
\hline$r_{t-3}$ & -0.0346 & -0.2030 & & & & & & \\
\hline$r_{t-4}$ & -0.0282 & -0.2363 & & & & & & \\
\hline Constant & -0.3145 & -0.7918 & & & & & & \\
\hline$\overline{\mathrm{RSS}}$ & & 0.0135 & & 0.0153 & & 0.0157 & & 0.0159 \\
\hline sigma & & 0.0128 & & 0.0127 & & 0.0128 & & 0.0129 \\
\hline $\mathrm{R}^{2}$ & & 0.9998 & & 0.9998 & & 0.9998 & & 0.9998 \\
\hline $\operatorname{Radj}^{2}$ & & 0.8038 & & 0.9312 & & 0.9311 & & 0.9311 \\
\hline LogLik & & 455.5085 & & 449.0368 & & 447.8882 & & 447.2097 \\
\hline AIC & & -8.5394 & & -8.6674 & & -8.6449 & & -8.6316 \\
\hline HQ & & -8.3310 & & -8.5944 & & -8.5719 & & -8.5586 \\
\hline $\mathrm{SC}$ & & -8.0247 & & -8.4872 & & -8.4647 & & -8.4514 \\
\hline Chow(1967:4) & 0.4367 & 0.9958 & 0.5440 & 0.9814 & 0.5418 & 0.9820 & 0.5243 & 0.9864 \\
\hline Chow(1973:4) & 0.5427 & 0.9064 & 0.4743 & 0.9470 & 0.4374 & 0.9628 & 0.4716 & 0.9483 \\
\hline normality test & 6.1768 & 0.0456 & 6.1584 & 0.0460 & 5.8507 & 0.0536 & 6.0494 & 0.0486 \\
\hline AR $1-5$ test & 0.9351 & 0.4631 & 1.2622 & 0.2872 & 1.3347 & 0.2569 & 1.4750 & 0.2058 \\
\hline hetero test & 0.8275 & 0.7223 & 1.3887 & 0.1781 & 1.4050 & 0.1703 & 1.4021 & 0.1717 \\
\hline
\end{tabular}




\section{Conclusions and new directions}

The aim of the paper was to evaluate econometric model-selection strategies and see if they worked well, indifferently, or failed badly. The results come much closer to the former: the diagnostic-test operational characteristics are fine; selection-test probabilities match those relevant to the DGP; and deletion-test probabilities show $1 \%$ retention at a nominal $1 \%$ when no sub-sample testing is used.

We also found that, although estimates are 'biased' on average, conditional on retaining a variable, the parameter estimates were close to unbiased. This is essential for economic policy - if a variable is included, PcGets delivers the right response; otherwise, when it is excluded, one is simply unaware that such an effect exists.

On two empirical modelling problems, given the GUM that earlier investigators used, PcGets selects either closely similar, or somewhat improved specifications.

Can one beat the baseline nominal selection probabilities? First, since the diagnostic tests are insignificant at every stage, PcGets avoids spurious inclusion of a variable simply because of the wrong standard error (e.g., from residual autocorrelation). Thus, it could attain the same lower bound as in a pure white-noise setting. Secondly, path choices seem to have little effect, as every selection must remain both congruent and encompassing. Thirdly, post-selection tests may reduce the probability of including non-DGP variables below the nominal size of the t-tests, at possible costs in terms of the power of retaining relevant variables, and possibly the diagnostics becoming significant. Although the costs of missing 'real' influences rise then, the power-size trade off in Hoover and Perez (1999) is quite flat around an 80-20 split.

So far, we have not discussed the role of structural breaks, particularly in regressors, both in sample, and after selection. In general, breaks in regressors in-sample should not alter the selection probabilities: there is still an $\alpha$ chance for false inclusion, but different variables will be selected. However, breaks after selection, as the sample grows, should help to eliminate adventitious influences. PcGets tests for constancy as one diagnostic, and conducts sub-sample evaluation of reliability, but does not make 'decisions' based on the latter information. In a PRS, however, such accrual of information is essential.

Various other extensions of the algorithm developed in this paper are worth exploring. One area of possible extensions of PcGets concerns the pre-selection of variables. For example, one could fix economically-essential variables, then apply PcGets to the remaining orthogonalized variables. Forced search paths may merit inclusion (e.g., all even-numbered variables in an MC; economically-relevant selected sets in empirical modelling). Suppose two investigators commenced with distinct subsets of the GUM, would they converge to the same reduction path if, after separate reduction exercises, they conducted encompassing tests, and recommenced from the union of their models? Such a search could be a 'forced' path in the algorithm, and may well be a good one to follow, but remains a topic for future research. Implementing cointegration reductions and other linear transforms could also help here.

The focus of this paper was on general-to-specific selection strategies. Further work comparing Gets on the same data to simple-to-general approaches, and other strategies such as simply using information criteria to select, are merited. More detailed Monte Carlo studies are required to investigate the impacts of breaks (interacting with the effects of sub-sample selection), collinearity, integration and cointegration. 


\section{References}

Abramowitz, M., and Stegun, N. C. (1970). Handbook of Mathematical Functions. New York: Dover Publications Inc.

Bock, M. E., Yancey, T. A., and Judge, G. C. (1973). Statistical consequences of preliminary test estimators in regression. Journal of the American Statistical Association, 68, 109-116.

Box, G. E. P., and Pierce, D. A. (1970). Distribution of residual autocorrelations in autoregressiveintegrated moving average time series models. Journal of the American Statistical Association, 65, 1509-1526.

Chow, G. C. (1960). Tests of equality between sets of coefficients in two linear regressions. Econometrica, 28, 591-605.

Chow, G. C. (1981). Selection of econometric models by the information criteria. In Charatsis, E. G. (ed.), Proceedings of the Econometric Society European Meeting 1979, C.H. 8. Amsterdam: North-Holland.

Davidson, J. E. H., and Hendry, D. F. (1981). Interpreting econometric evidence: Consumers' expenditure in the UK. European Economic Review, 16, 177-192. Reprinted in Hendry, D. F. (1993), Econometrics: Alchemy or Science? Oxford: Blackwell Publishers.

Davidson, J. E. H., Hendry, D. F., Srba, F., and Yeo, S. (1978). Econometric modelling of the aggregate time-series relationship between consumers' expenditure and income in the United Kingdom. Economic Journal, 88, 661-692.

Doornik, J. A. (1998). Object-Oriented Matrix Programming using Ox 2.0. London: Timberlake Consultants Press.

Doornik, J. A., and Hansen, H. (1994). A practical test for univariate and multivariate normality. Discussion paper, Nuffield College.

Doornik, J. A., and Hendry, D. F. (1992). PcGive 7: An Interactive Econometric Modelling System. Oxford: Institute of Economics and Statistics, University of Oxford.

Godfrey, L. G. (1978). Testing for higher order serial correlation in regression equations when the regressors include lagged dependent variables. Econometrica, 46, 1303-1313.

Harvey, A. C. (1981). The Econometric Analysis of Time Series. Deddington: Philip Allan.

Hendry, D. F. (1979). Predictive failure and econometric modelling in macro-economics: The transactions demand for money. In Ormerod, P. (ed.), Economic Modelling, pp. 217-242. London: Heinemann. Reprinted in Hendry, D. F. (1993), Econometrics: Alchemy or Science? Oxford: Blackwell Publishers.

Hendry, D. F. (1984). Monte Carlo experimentation in econometrics. In Griliches, Z., and Intriligator, M. D. (eds.), Handbook of Econometrics, Vol. 2-3, C.H. 16. Amsterdam: North-Holland.

Hendry, D. F. (1993). Econometrics: Alchemy or Science? Oxford: Blackwell Publishers.

Hendry, D. F. (1995). Dynamic Econometrics. Oxford: Oxford University Press.

Hendry, D. F., and Doornik, J. A. (1996). Empirical Econometric Modelling using PcGive 9 for Windows. London: Timberlake Consultants Press.

Hendry, D. F., and Ericsson, N. R. (1991a). An econometric analysis of UK money demand in 'Monetary Trends in the United States and the United Kingdom by Milton Friedman and Anna J. Schwartz'. American Economic Review, 81, 8-38.

Hendry, D. F., and Ericsson, N. R. (1991b). Modeling the demand for narrow money in the United 
Kingdom and the United States. European Economic Review, 35, 833-886.

Hendry, D. F., and Krolzig, H.-M. (1999a). General-to-specific model specification using PcGets for Ox. Discussion paper, Institute of Economics and Statistics, Oxford University.

Hendry, D. F., and Krolzig, H.-M. (1999b). Pcgets: improving the results in 'data mining reconsidered' by K.D. Hoover and S.J. Perez. Mimeo, Oxford Institute of Economics and Statistics, Oxford.

Hendry, D. F., and Richard, J.-F. (1989). Recent developments in the theory of encompassing. In Cornet, B., and Tulkens, H. (eds.), Contributions to Operations Research and Economics. The XXth Anniversary of CORE, pp. 393-440. Cambridge, MA: MIT Press.

Hoover, K. D., and Perez, S. J. (1999). Data mining reconsidered: Encompassing and the general-tospecific approach to specification search. Econometrics Journal, 2, 1-25.

Jarque, C. M., and Bera, A. K. (1980). Efficient tests for normality, homoscedasticity and serial independence of regression residuals. Economics Letters, 6, 255-259.

Judge, G. G., and Bock, M. E. (1978). The Statistical Implications of Pre-Test and Stein-Rule Estimators in Econometrics. Amsterdam: North Holland Publishing Company.

Leamer, E. E. (1983). Let's take the con out of econometrics. American Economic Review, 73, 3143. Reprinted in Granger, C. W. J. (ed.) (1990), Modelling Economic Series. Oxford: Clarendon Press.

Lovell, M. C. (1983). Data mining. Review of Economics and Statistics, 65, 1-12.

Mayo, D. (1981). Testing statistical testing. In Pitt, J. C. (ed.), Philosophy in Economics, pp. 175-230: D. Reidel Publishing Co. Reprinted as pp. 45-73 in Caldwell B. J. (1993), The Philosophy and Methodology of Economics, Vol. 2, Aldershot: Edward Elgar.

Mizon, G. E., and Richard, J. F. (1986). The encompassing principle and its implication to testing non-nested hypotheses. Econometrica, 54, 657-678.

Neyman, J., and Pearson, E. S. (1928). On the use and interpretation of certain test criteria for purposes of statistical inference. Biometrika, 20A, 175-240, 263-294.

Nicholls, D. F., and Pagan, A. R. (1983). Heteroscedasticity in models with lagged dependent variables. Econometrica, 51, 1233-1242.

Pagan, A. R. (1987). Three econometric methodologies: A critical appraisal. Journal of Economic Surveys, 1, 3-24. Reprinted in Granger, C. W. J. (ed.) (1990), Modelling Economic Series. Oxford: Clarendon Press.

Sawa, T. (1978). Information criteria for discriminating among alternative regression models. Econometrica, 46, 1273-1292.

Sims, C. A., Stock, J. H., and Watson, M. W. (1990). Inference in linear time series models with some unit roots. Econometrica, 58, 113-144.

White, H. (1980). A heteroskedastic-consistent covariance matrix estimator and a direct test for heteroskedasticity. Econometrica, 48, 817-838.

White, H. (1990). A consistent model selection. In Granger, C. W. J. (ed.), Modelling Economic Series, pp. 369-383. Oxford: Clarendon Press.

Wooldridge, J. M. (1999). Asymptotic properties of some specification tests in linear models with integrated processes. In Engle, R. F., and White, H. (eds.), Cointegration, Causality and Forecasting, pp. 366-384. Oxford: Oxford University Press. 